\title{
PENSANDO SOBRE MOBILIDADE, DIETA E MUDANÇA SOCIAL: ANÁLISES ISOTÓPICAS NO SÍTIO ARMAÇÃO DO SUL, FLORIANÓPOLIS/SC
}

THINKING ABOUT MOBILITY, DIET, AND SOCIAL CHANGE: ISOTOPIC ANALYSIS AT THE ARMAÇÃO DO SUL SITE, FLORIANÓPOLIS/SC

Gabriela Oppitz

Murilo Quintans Ribeiro Bastos

Luciane Zanenga Scherer

Andrea Lessa

Veridiana Martins

Plínio Camargo

Paulo DeBlasis

Como citar este artigo:

OPPITZ, Gabriela; BASTOS, Murilo Quintans Ribeiro; SCHERER, Luciane Zanenga; LESSA, Andrea; MARTINS, Veridiana; CAMARGO, Plínio; DEBLASIS, Paulo. Pensando sobre mobilidade, dieta e mudança social: análises isotópicas no sítio Armação do Sul, Florianópolis/SC. In: Cadernos do Lepaarq, v. XV, n.30., p. 237-266, Jul-Dez. 2018. 


\title{
Pensando sobre mobilidade, dieta e mudança social: análises isotópicas no sítio Armação do Sul, Florianópolis/SC
}

\author{
Gabriela Oppitz \\ Murilo Quintans Ribeiro Bastos ${ }^{\mathrm{b}}$ \\ Luciane Zanenga Scherer ${ }^{c}$ \\ Andrea Lessa $^{\mathrm{b}}$ \\ Veridiana Martins ${ }^{\mathrm{d}}$ \\ Plínio Camargo ${ }^{e}$ \\ Paulo DeBlasis ${ }^{\mathrm{f}}$
}

\begin{abstract}
Resumo: Há uma intensificação nos processos de mudança associados aos sítios conchíferos do litoral catarinense a partir de 2000 AP, marcada por acontecimentos como a diminuição no número de sítios, a diminuição no uso de conchas em sua formação e o aparecimento da cerâmica. Com o objetivo de compreender melhor essas mudanças e entendendo o sítio Armação do Sul(Florianópolis/SC) como elemento chave para essa compreensão, foram realizadas análises isotópicas de estrôncio $\left({ }^{87} \mathrm{Sr} /{ }^{86} \mathrm{Sr}\right)$, carbono $(\delta 13 \mathrm{C})$ e nitrogênio $(\delta 15 \mathrm{~N})$ nos indivíduos que nele se encontram sepultados, juntamente com o estabelecimento de uma cronologia estratigraficamente referenciada. Os resultados obtidos indicam que os processos de mudança se desenrolaram diferentemente em porções distintas do litoral catarinense e que, no caso do sítio Armação do Sul, as mudanças observadas estão relacionadas a um quadro que envolve maior circulação e incorporação de indivíduos, de diferentes partes do litoral central, e mudança na dieta dos indivíduos do sexo masculino.
\end{abstract}

\section{Palavras Chave:}

Isótopos Estáveis; Mudança; Sítios Conchíferos; Litoral Catarinense.

\begin{abstract}
There is an intensification in the processes of change associated with the shell-matrix sites of the Santa Catarina coast from 2000 BP onwards, marked by events such as the decrease in the number of sites, the decrease in the use of shells in their formation and the introduction of pottery. To better understand these changes, and taking the Armação do Sul site (Florianópolis/SC) as a key element in this understanding, we performed strontium $\left({ }^{87} \mathrm{Sr} /{ }^{86} \mathrm{Sr}\right)$, carbon $(\delta 13 \mathrm{C})$ and nitrogen $(\delta 15 \mathrm{~N})$ isotopic analyzes on the individuals buried there, together with the establishment of a stratigraphically referenced chronology. The results indicate that the processes of change occurred differently in different parts of the Santa Catarina coast and that, in the case of the Armação do Sul site, the observed changes are related to an increased circulation and incorporation of individuals from different parts of the central coast and dietary change in male individuals.
\end{abstract}

\section{Keywords:}

Stable Isotopes; Change; Shell-Matrix Sites; Santa Catarina Coast.

$\boldsymbol{a}$ Doutoranda do Programa de Pós-Graduação em Antropologia, Universidade de Stanford, Estados Unidos. Este artigo é uma adaptação de parte da dissertação de mestrado intitulada "Coisas que mudam: os processos de mudança nos sítios conchíferos catarinen-ses e um olhar isotópico sobre o caso do sítio Armação do Sul, Florianópolis/SC", defendida em agosto de 2015 no Museu de Arqueologia e Etnologia da Universidade de São Paulo (MAE/USP), Brasil. A pesquisa foi desenvolvida com Bolsa da Coordenação de Aperfeiçoamento de Pessoal de Nível Superior (CAPES), Brasil; e financiamento da Fundação de Amparo à Pesquisa do Estado de S. Paulo (FAPESP), Brasil; (2013/11193-4). E-mail: oppitz@stanford.edu/gabrielaoppitz@gmail.com.

$\boldsymbol{b}$ Museu Nacional, Universidade Federal do Rio de Janeiro (MN/UFRJ), Brasil.

$c$ Museu de Arqueologia e Etnologia, Universidade Federal de Santa Catarina (MArquE/ UFSC), Brasil.

$\boldsymbol{d}$ Instituto de Geociências, Universidade de São Paulo (USP), Brasil.

$\boldsymbol{e}$ Centro de Energia Nuclear na Agricultura, Universidade de São Paulo (USP), Brasil.

$f$ Museu de Arqueologia e Etnologia, Universidade de São Paulo (MAE/USP), Brasil. 


\section{INTRODUÇÃO E CONTEXTO DE PESQUISA}

Se pensado em termos cronológicos, o processo de ocupação pré-colonial do litoral de Santa Catarina é bastante semelhante para as porções litorâneas norte (entendida aqui como a região da baía da Babitonga), central (Ilha de Santa Catarina, ilhas adjacentes e continente próximo) e sul (entendida aqui como a região de Laguna, Tubarão e Jaguaruna)' ${ }^{1}$, e esta semelhança cronológica vem acompanhada por alguns fenômenos que são recorrentes ao longo da costa catarinense.

Após um período de cerca de 4 mil anos (entre 6.000 e 2.000 anos AP), ao longo do qual as populações associadas aos sambaquis se estabeleceram na faixa costeira e deram origem ao contexto arqueológico que nos é conhecido, período ao qual DeBlasis et al. (2007) se referem como "era sambaquieira" e que é marcado por uma aparente estabilidade² na vivência de mundo dessas populações, tem início um novo momento, mais curto (entre 2.000 e 600 anos AP), que ninguém ainda sabe ao certo o que significou.

A partir de $2.000 \mathrm{AP}$, há uma diminuição na formação de novos sítios e ocorre uma mudança aparentemente repentina nos padrões deposicionais de diversos sambaquis, período em que passam a ser formados por um sedimento de coloração escura, com grande quantidade de matéria orgânica, como carvão e ossos de peixes. No caso do sítio Jabuticabeira II - que até o momento foi o mais detalhadamente estudado - apesar da variação composicional, nesta camada escura mantêm-se os processos construtivos associados às estruturas funerárias, bem como as características das indústrias lítica e óssea (Bendazzoli 2007, DeBlasis et al. 2007, Nishida 2007, DeBlasis e Gaspar 2008/2009, Villagran 2008, Villagran et al. 2010). No momento seguinte, a partir de $1.500 \mathrm{AP}$, começa a aparecer cerâmica nos horizontes superficiais de alguns sambaquis e em sítios conchíferos rasos ${ }^{3}$, cerâmica esta que costuma ser atribuída a grupos da família linguística Jêe e que vem acompanhada por algumas mudanças em conteúdo e estratigrafia que, contudo, não parecem constituir uma ruptura ou mudança estrutural absoluta ( $c f$. Villagran 2012). Trata-se, portanto, não apenas de mudança, mas também de continuidade.

Em um olhar retrospectivo que tenta englobar 5 mil anos de história num único e distanciado instante de apreciação, essas são as mudanças - e continuidades - mais perceptíveis no contexto geral dos sítios conchíferos do litoral catarinense. Se, no entanto, aproximarmos nosso olhar, veremos que as transformações e permanências são múltiplas e multidimensionais, variando conforme o olhar empregado, a escala temporal e espacial escolhida e o material analisado. Incluem o aumento da violência (Lessa e Scherer 2008); a manutenção no registro paleogenético das populações, porém com entrada de novo patrimônio genético em alguns sítios (Neves 1988, Okumura 2008); a alteração para um padrão de residência virilocal (Hubbe $e t$ al. 2009); a manutenção de uma dieta predominantemente marinha, porém algumas vezes acompanhada de uma diminuição no consumo desse tipo de recurso e de variações locais na diversidade e quantidade desses alimentos (Bandeira 1992; Figuti

1 Quando falamos em semelhança cronológica, estamos nos referindo à sequência do processo de ocupação: início e fim da formação de sambaquis e outros sítios conchíferos, seguido da chegada das populações Guarani à costa, de acordo com datações apresentadas em De Masi (2001), Bandeira (2004), DeBlasis et al. (2007), Giannini et al. (2010), Milheira (2010), Müller (2014).

2 Um período como esse, de 4 mil anos, com certeza não foi desacompanhado de mudanças e não pode ser entendido como estático e homogêneo. Imaginamos que estudos futuros permitirão a desconstrução de tal impressão de "estabilidade", dinamizando esses tempos mais antigos da ocupação costeira.

3 A noção de "sítio conchífero" foi desenvolvida em Oppitz (2015), para se referir aos sambaquis e sítios rasos com e sem presença de cerâmica a partir de uma perspectiva de longa duração, desvelando as continuidades existentes em meio às descontinuidades e fazendo-as prevalecer. "Sítio conchífero raso", portanto, refere-se aos sítios que Rohr (1984) costumava chamar de "sítio raso de sepultamento" e que, mais recentemente, Villagran (2012:82) - ver também Giannini (2010:111) - chamou de “montículos ictiológicos”: sítios ou camadas sobre sítios "formados por misturas maciças ou mal estratificadas de areia com ossos de peixe, carvão, conchas ocasionais e, em alguns casos, fragmentos cerâmicos".

4 Desde que Chmyz $(1967,1968)$ estabeleceu a tradição Itararé e apontou para a semelhança entre a cerâmica desta tradição e aquela produzida pelos indígenas Kaingáng aldeados em Palmas, no Estado do Paraná. 
1993; Klökler 2001, 2014; De Masi 2001, 2009; Bastos et al. 2014, 2015; Colonese et al. 2014); a manutenção no consumo de amido e na baixa frequência e prevalência de cáries, porém com variações locais (Wesolowski 2007); a introdução da cerâmica e seu uso no processamento de alimentos marinhos (Hansel 2006, Colonese et al. 2014).

Embora a sintonia cronológica entre esses acontecimentos aponte para um único e amplo processo de ocupação e transformação para o litoral catarinense inteiro, um olhar mais atento sobre os contextos arqueológicos das três porções litorâneas permite entrever diferenças e particularidades que levam à ideia de processos distintos, porém condicionados pelos mesmos eventos primordiais. Processos que se interseccionam em determinados pontos no tempo e no espaço, porém que se desenrolam de forma desigual quanto à direção, à intensidade, aos atores envolvidos e outros elementos, diferenciando-se para, em longo prazo, diferenciar também cada um dos contextos locais.

Esse processo de diferenciação, no entanto, parece ter decorrido de forma mais intensa no litoral central, onde o panorama arqueológico pré-colonial atualmente conhecido apresenta-se mais acentuadamente peculiar se comparado àquele conhecido para as porções litorâneas que lhe são adjacentes ao norte e ao sul. Tal peculiaridade é denunciada por aspectos como as menores dimensões dos sambaquis (Oppitz 2011); a maior ocorrência de sítios conchíferos com presença de cerâmica (Bandeira 2004, Fossari 2004, Farias e Kneip 2010); a maior ocorrência de oficinas líticas (CNSA/IPHAN); e, sobretudo, a ocorrência de inscrições rupestres, especificidade do litoral central de Santa Catarina no contexto litorâneo nacional (Comerlato 2005).

Com o objetivo de compreender melhor esses processos de mudança e entendendo o sítio Armação do Sul (Florianópolis/SC) como elemento chave para essa compreensão, foram realizadas análises isotópicas de estrôncio $\left({ }^{87} \mathrm{Sr} /{ }^{86} \mathrm{Sr}\right)$, carbono $\left(\delta^{13} \mathrm{C}\right)$ e nitrogênio $\left(\delta^{15} \mathrm{~N}\right)$ nos indivíduos nele sepultados, juntamente com o estabelecimento de uma cronologia que associou informação estratigráfica com datações radiocarbônicas obtidas para diversos esqueletos.

A análise das razões isotópicas de diversos elementos químicos estáveis tem se mostrado uma importante ferramenta para a determinação de paleodietas e padrões de mobilidade das populações do passado, bem como para reconstruções paleoambientais. Os isótopos de nitrogênio e carbono são, dentre aqueles que vêm sendo utilizados para o estudo de paleodietas, os mais comumente utilizados (DeNiro e Epstein 1978, 1981; Schoeninger, DeNiro e Tauber 1983; Walker e DeNiro 1986; Ambrose 1993; Katzenberg e Harrison 1997; Makarewicz eSealy 2015). Os isótopos de estrôncio, por outro lado, figuram entre os mais eficazes quando se trata de caracterizar mobilidade humana e animal (Price et al. 2002; Grupe et al. 1997; Montgomery 2003; Bentley, Krause e Price 2003; Bentley 2006; Knudson et al. 2004; Wright 2005; Makarewicz e Sealy 2015).

A partir de uma perspectiva de longa duração (Braudel 1984, 1992) centrada na prática (Bourdieu 1967, 1977; Sahlins 1985) e do reconhecimento da multidimensionalidade inerente aos processos de mudança, os dados gerados foram entendidos contextualmente na curta, média e longa duração, e em escala de sítio (Armação do Sul), local (litoral central) e regional (litoral catarinense). Tal perspectiva teve diversas implicações sobre a forma como os dados gerados ao longo da pesquisa foram interpretados, como será demonstrado ao longo deste artigo.

\section{O SÍTIO ARMAÇÃO DO SUL}

Situado em praia de mesmo nome na porção sul da Ilha de Santa Catarina (Figura 1), o sítio Armação do Sul foi escavado por João Alfredo Rohr em duas etapas: uma em 1969, com a participação de Margarida Andreatta e publicação de nota prévia (Rohr e Andreatta 1969), e outra em 1974, cujos resultados foram publicados no jornal Correio do Povo, de Porto Alegre (Rohr 1974). Com uma área total estimada em $2000 \mathrm{~m}^{2}$, o sítio teve $269 \mathrm{~m}^{2}$ escavados $-85 \mathrm{~m}^{2}$ na primeira etapa e $184 \mathrm{~m}^{2}$ 

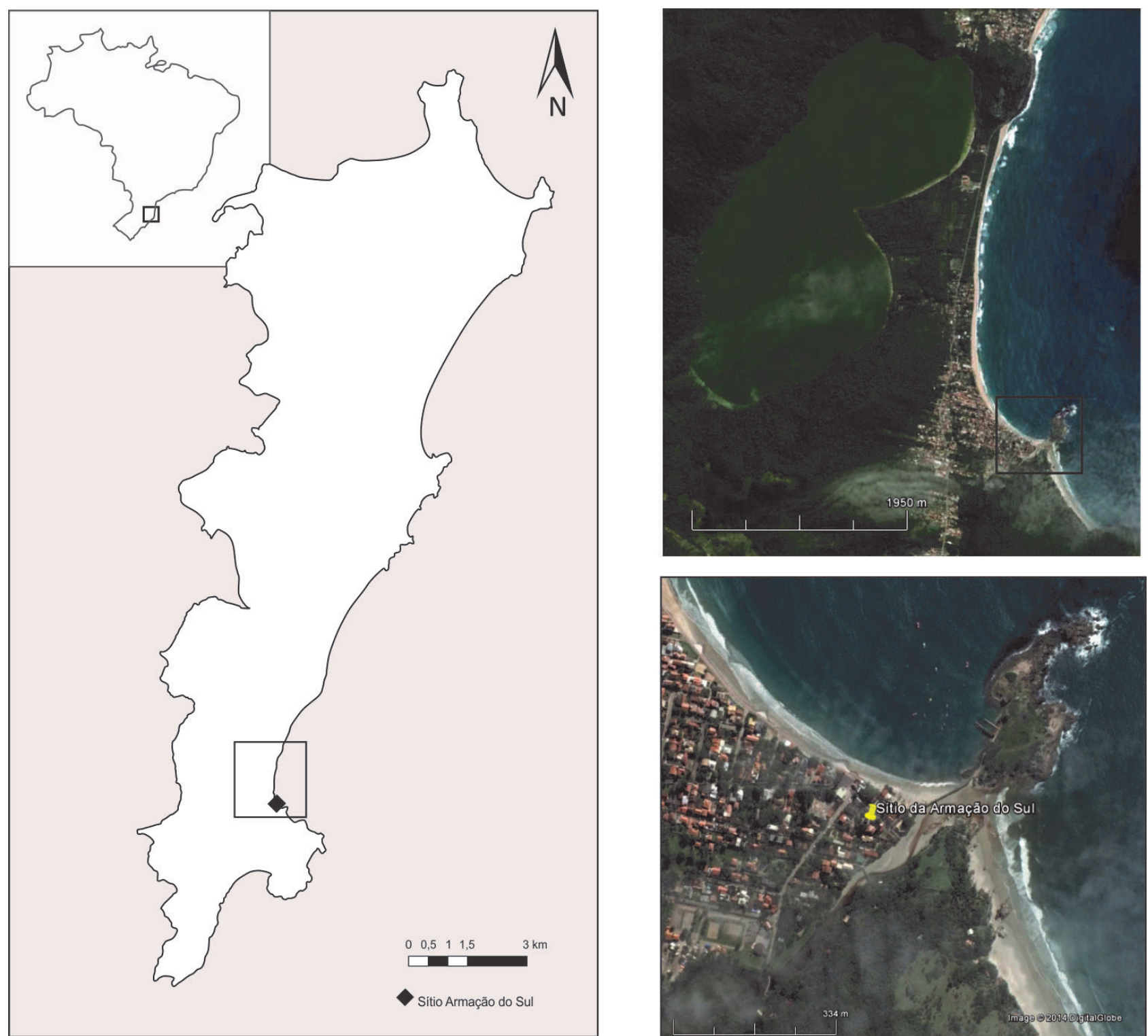

Figura 1: Localização do sítio Armação do Sul, na Ilha de Santa Catarina, e detalhe da planície costeira da praia da Armação, onde ele se situa.

na segunda, com $10 \mathrm{~m}$ de distância entre as duas áreas - sendo atingidos $2 \mathrm{~m}$ de profundidade.

O material proveniente dessas intervenções hoje se encontra no Museu do Homem do Sambaqui “Pe. João Alfredo Rohr, S.J.”, no Colégio Catarinense (Florianópolis/SC), incluindo a coleção esquelética referente aos 86 sepultamentos escavados, alvo de análise nesta pesquisa.Com base no diário de campo de Rohr, perfis, plantas e fotografias geradas ao longo da pesquisa, a equipe do Instituto Anchietano de Pesquisas realizou a curadoria e o estudo posterior do material retirado do sítio, com exceção dos remanescentes humanos, que foram curados em projeto executado pela Me. Luciane Zanenga Scherer. Os dados das escavações, o resultado das análises e demais interpretações desenvolvidas podem ser encontradas em Schmitz et al. (1992).

O sítio Armação do Sul foi escolhido como estudo de caso porque diverge dos sambaquis, tendo em vista a pouca quantidade de conchas em sua composição, mas, como não apresenta cerâmica, tampouco se enquadra junto aos sítios cerâmicos rasos mais tardios. Além disso, ele apresenta mudança no sedimento que o compõe, passando de areia marrom escura no nível inferior para terra preta no nível superior, e mudança nas práticas mortuárias, relacionada ao uso do ocre e outros elementos de acompanhamento funerário (Figura 2). Ele é também, até o momento, o único sítio conchífero sem cerâmica do 


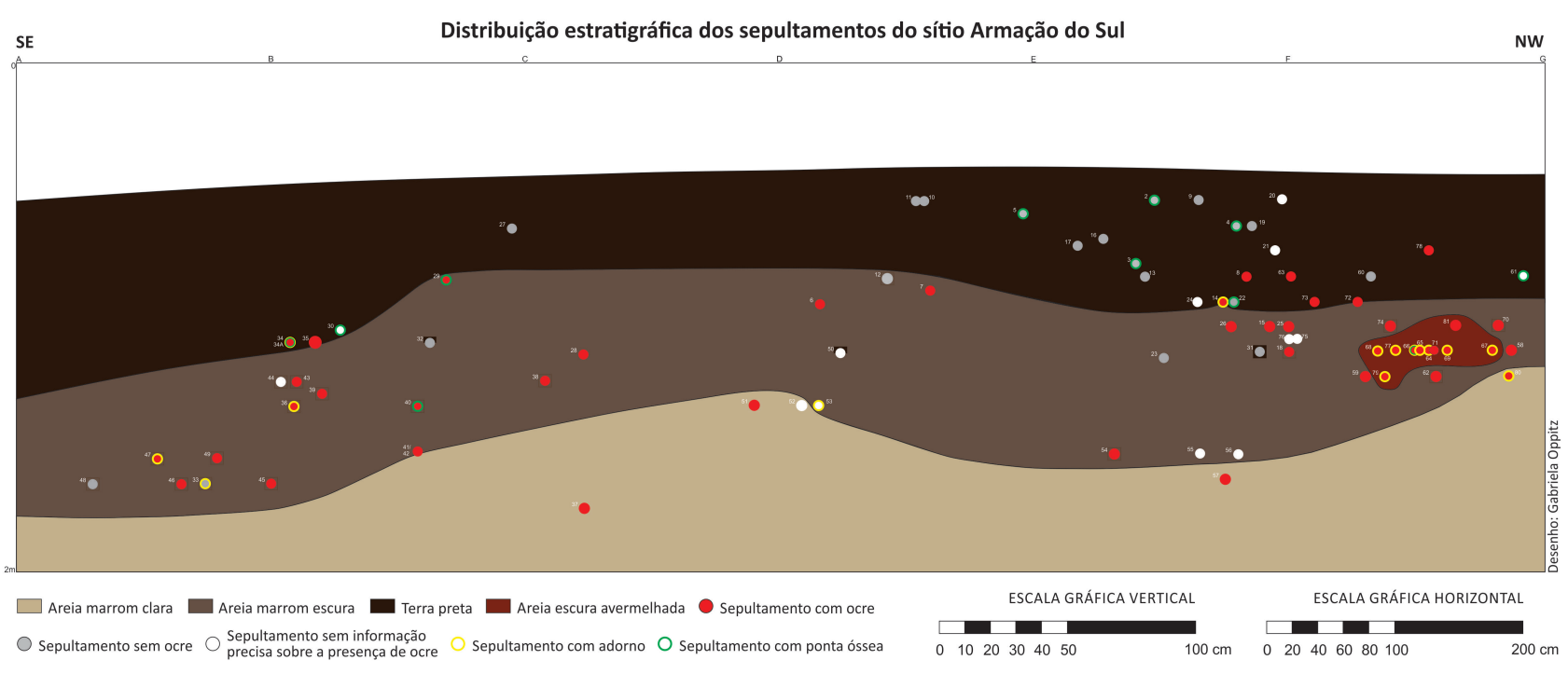

Figura 2: Distribuição estratigráfica dos sepultamentos do sítio Armação do Sul. Nota-se que o croqui representa, em um plano vertical bidimensional, um espaço tridimensional de $85 \mathrm{~m}^{2}$ e $2 \mathrm{~m}$ de profundidade. Tendo em vista as irregularidades na topografia da área escavada, os limites entre as camadas foram estabelecidos com base nos sepultamentos e nas informações sobre o tipo de sedimento em que estavam envolvidos.

litoral catarinense que apresenta caso de indivíduo com evidência de violência (Lessa e Scherer 2008).

As datações realizadas em 30 indivíduos indicam que o sítio Armação do Sul foi utilizado para atividades funerárias entre $2900 \pm 30$ e $1430 \pm 30$ anos AP, que as mudanças observadas no sedimento e nas práticas mortuárias tiveram início entre 2400 e 2300 AP, e que o indivíduo com evidência de violência possui idade de $1550 \pm 30$ anos AP (detalhes das datações podem ser conferidos em Oppitz 2015). Permite também o estabelecimento de uma cronologia que associa as idades obtidas às informações estratigráficas, com a divisão dos mais de 1000 anos de ocupação do sítio em Período 1 (3000-2500 anos AP) e Período 2 (2500-1200 anos AP).

Assim, o sítio Armação do Sul parece incorporar algumas das continuidades e descontinuidades dos sítios do litoral catarinense, mostrando-se sintonizado com aquilo que estava acontecendo a nível regional, e, ao mesmo tempo, apresenta características particulares que remetem ao caráter peculiar do panorama arqueológico do litoral central e àquelas relações que estavam sendo empreendidas a nível local. E, por esse motivo, está sendo tomado como elemento chave para entender tanto as particularidades do processo de ocupação que diferenciou o litoral central das demais porções litorâneas catarinenses, quanto as mudanças que se deram em nível regional, a partir de $2.000 \mathrm{AP}$, culminando no aparecimento da cerâmica e no posterior fim das práticas associadas à formação de sítios conchíferos.

\section{INTERPRETANDO A MUDANÇA: LONGA DURAÇÃO, TEORIA DA PRÁTICA E MULTIDIMENSIONALIDE}

Um primeiro passo a ser tomado para a interpretação das mudanças no sítio Armação do Sul e demais sítios conchíferos do litoral catarinense é o estabelecimento de uma perspectiva de longa duração, conferindo continuidade histórica entre sambaquis e sítios conchíferos rasos, e entre ocupações sem e com presença de cerâmica. Essa perspectiva aglutina todos os sítios litorâneos com presença não negligenciável de conchas sob uma noção mais geral de "sítios conchíferos", que nada mais é que um artifício para reestruturação mental no sentido de escapar à compartimentação, desvelando as continuidades existentes em meio às descontinuidades e fazendo-as prevalecer. A diacronia dos tempos de Braudel (1984, 1992) ajuda-nos a perceber a fluidez e o caráter processual da mudança. O modelo braudeliano, contudo, não se faz suficiente para o entendimento da mudança no registro arqueológico por um simples motivo: de acordo com Braudel (2005 [1958]), não há espaço 
para a sincronia no tempo histórico; e a diacronia sozinha não dá conta de revelar as variações formais resultantes de desenrolamentos locais, nem os mecanismos de mudança.

Como as coisas mudam, afinal? Braudel não está preocupado com isso. As atualizações da estrutura, e a forma como essas atualizações se dão - justamente no cruzamento do diacrônico com o sincrônico - não importam. O que de fato lhe importa é medir a duração precisa dos movimentos, matematicamente; "observar o entrecruzamento desses movimentos, sua interação e seus pontos de ruptura" (Braudel 2005[1985]: 73). Estrutura, conjuntura e evento fazem parte de um modelo desenvolvido para a medição do tempo. São categorizações, congelamentos analíticos de uma história movente, pensados como uma forma de observar os processos históricos e torná-los mais facilmente manuseáveis.

De todo modo, a perspectiva de longa duração tem importantes implicações para a forma como os dados gerados ao longo desta pesquisa são tratados e interpretados, convertendo diferença em transformação. O reconhecimento de continuidade histórica em meio às descontinuidades pressupõe uma sociedade litorânea que se transforma no tempo, e não a chegada de grupos agricultores provenientes do planalto. Assim, aquilo que era diferença estatisticamente significativa vira mudança significativa, aquilo que era incomparável - teórica e analiticamente - torna-se comparável. Com essa perspectiva inicial, é possível dar um novo tom à forma como se pensa a mudança no registro arqueológico da costa catarinense e, a partir daí, expandir as possibilidades interpretativas.

Assim, a estrutura de Braudel segue aqui como pano de fundo; pano de fundo para a ação, que pode ser encontrada na teoria da prática de Bourdieu $(1967,1977,1989)$ e na discussão de Sahlins (2011[1985]) sobre a relação entre história e estrutura. Os conceitos de "habitus" naquele e de "evento" neste último promovem uma síntese indissolúvel entre indivíduo e estrutura, curta e longa duração, local e regional, sincronia e diacronia, mudança e permanência, emprestando os mecanismos de mudança necessários ao dinamismo da estrutura de conteúdo de Braudel.

A implicação da teoria da prática de Bourdieu e Sahlins para a interpretação dos dados neste artigo se manifesta no entendimento de que a mudança se dá na negociação entre indivíduo e estrutura e, logo, acontecimentos regionais - e mesmo globais - são interpretados contextualmente, repercutindo diferentemente em diferentes locais. Ainda de acordo com essa percepção, a dieta é aqui entendida como meio potente de estruturação e transformação das sociedades, potência que se encontra justamente em seu caráter ordinário e cotidiano.

Essa perspectiva de longa duração centrada na prática leva ao reconhecimento da multidimensionalidade inerente aos processos de mudança. Multidimensionalidade significa coexistência de mudanças e ritmos de mudança em diferentes escalas espaciais e temporais, que vão desde as mais longas durações, como o tempo evolutivo e o tempo das estruturas sociais, até as durações mais curtas do tempo ritual e das atividades cotidianas. A partir do momento em que a multidimensionalidade é acionada, não se trata mais de uma única mudança, mas de uma rede complexa e entrecortada de mudanças diversas. Virilocalidade, cerâmica, aumento da violência, diminuição do nível do mar, aparecimento da terra preta, alteração na quantidade de sítios, nas práticas mortuárias, na dieta. A mudança é tudo isso e além; tudo isso ao mesmo tempo, e tudo isso em tempos distintos.

Para uma abordagem multidimensional, contudo, são necessárias também adequações do ponto de vista analítico, que aqui são feitas por meio de processamento estatístico igualmente multidimensional, sendo os resultados das análises isotópicas e das práticas mortuárias entendidos na curta, média e longa duração, e em escala de sítio (Armação do Sul), local (litoral central) e regional (litoral catarinense). Na escala de sítio, isso implicou pelo menos três níveis de análise: estabelecimento da tendência geral, comparação entre o primeiro e o segundo momento cronológico e posicionamento diacrônico dos indivíduos. Já para a contextualização local e regional dos resultados, foram realizadas comparações com dados provenientes de estudos 
em diferentes sítios do litoral catarinense (Bastos et al. 2011, 2014, 2015; Colonese et al. 2014; De Masi 2001, 2009). Vale destacar que a análise multidimensional dos dados só se fez possível devido a essa comparação com outros estudos e, sobretudo, devido à realização de datações individualizadas de diversos sepultamentos do sítio Armação do Sul.

A multidimensionalidade, associada à cronologia, torna os palimpsestos inteligíveis - e, sobretudo, faz com que sejam reconhecidos como palimpsestos - permitindo que aquilo que seria entendido apenas como variabilidade seja reconhecido como mudança ou distinção de sexo, idade e status. Permite, também, que aqueles elementos que remetem a tradições de maior duração e aqueles elementos que representam escolhas contingentes para a solução de situações eventuais sejam diferenciados, além de possibilitar a identificação de indivíduos estatisticamente atípicos ou anômalos (outliers), que jamais se destacariam dos demais se observados somente segundo a tendência geral.

Não basta compreendermos por que as coisas mudam, mas também como mudam. A história não vem em blocos de conteúdo que são trocados de tempos em tempos, a cada migração, mudança ambiental ou outro acontecimento de grande porte qualquer: a história é processo; a mudança, constante e processual - nisso aqueles momentos que costumamos chamar de "transição", tornam-se, simplesmente, momentos de maior agitação nos processos de mudança. Não são, afinal, os acontecimentos por si sós que movem a história, mas as interpretações que são feitas deles dentro de contextos específicos, na relação entre indivíduo e estrutura.

\section{MATERIAIS E MÉTODOS}

O elemento carbono possui dois isótopos estáveis, ${ }^{13} \mathrm{C}$ e ${ }^{12} \mathrm{C}$, o primeiro com abundância natural de aproximadamente $1,1 \%$ e o segundo com abundância de $98,9 \%$. A maior parte do carbono do mundo se encontra no oceano, mas ele está presente também na atmosfera, sob a forma de $\mathrm{CO}_{2}$. Esse carbono oceânico e atmosférico adentra o sistema biológico por meio do processo de fotossíntese das plantas verdes e do processo de quimiossíntese de bactérias que vivem em grandes profundidades marinhas (Schoeninger e Moore 1992).

O nitrogênio também possui dois isótopos estáveis, ${ }^{15} \mathrm{~N}$ e ${ }^{14} \mathrm{~N}$, o primeiro com abundância natural de $0,36 \%$ e o segundo com abundância de 99,64\%. A maior parte do nitrogênio do mundo está na atmosfera, sob a forma de $\mathrm{N}_{2}$, ou dissolvido no oceano. Esse nitrogênio adentra o sistema biológico por meio de organismos fixadores de $\mathrm{N}_{2}$, como algas azuis e verdes, de ambientes marinhos ou de água doce, e bactérias que formam nódulos nas raízes das leguminosas. E, também, pela decomposição bacteriana de moléculas complexas, possuidoras de nitrogênio após a morte dos organismos, processo no qual são produzidos nitratos que podem ser utilizados diretamente por plantas vasculares (Schoeninger e Moore 1992).

Por meio da alimentação, as diferentes composições isotópicas presentes na base da cadeia alimentar são adquiridas pelos animais e humanos. Como os valores $\delta^{15} \mathrm{~N}$ e $\delta^{13} \mathrm{C}$ variam entre diferentes tipos de plantas $\left(\mathrm{C}_{3}, \mathrm{C}_{4}\right.$, CAM, leguminosas e não leguminosas) e entre diferentes ambientes (terrestre, marinho, água doce), e, ainda, passam por enriquecimento trófico através da cadeia alimentar, com a análise da composição isotópica dos animais e humanos podemos estimar sua dieta, desde que o tecido a ser analisado seja devidamente isolado dos demais (DeNiro e Epstein 1978, 1981; Schoeninger, DeNiro e Tauber 1983; Walker e DeNiro 1986; Ambrose 1993). Nesse sentido, os valores $\delta^{13} \mathrm{C}$ obtidos podem indicar se a dieta era baseada em plantas $\mathrm{C}_{3}$ (trigo, arroz, gramíneas de montanha e áreas alagadas, tubérculos, bulbos e raízes tuberosas, legumes vegetais, nozes, mel e frutas) ou $\mathrm{C}_{4}$ (sorgo, milhetes, milho, cana-de-açúcar, gramíneas tropicais e alguns amarantos). E, embora os valores das plantas $\mathrm{C}_{4}$ possam se sobrepor aos valores marinhos, podem também auxiliar na diferenciação entre dietas marinhas e terrestres. Os valores $\delta^{15} \mathrm{~N}$, por sua vez, podem indicar o consumo relativo de leguminosas e não leguminosas, de recursos 
terrestres e recursos marinhos e, ainda, dar uma estimativa do nível trófico ocupado pelo indivíduo analisado.

Para a determinação dos valores $\delta^{15} \mathrm{~N}$ e $\delta^{13} \mathrm{C}$ do colágeno foram analisadas 35 amostras humanas, havendo preferência por fragmentos de costela, e 14 amostras de fauna oriundas do próprio sítio. As amostras foram: 1. Higienizadas com água

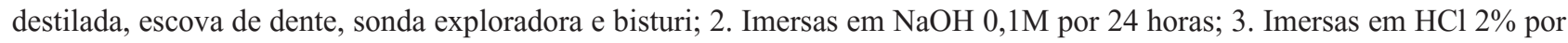
24 horas (etapa que foi repetida mais duas vezes); 4. Imersas novamente em NaOH por 24 horas; 5. Imersas em solução na proporção de 2:1:0,8 de metanol, clorofórmio e água destilada; 6 . Enxaguadas em água destilada e secas a $50^{\circ} \mathrm{C}$ em estufa. A determinação da composição isotópica e as porcentagens de carbono e nitrogênio das amostras de colágeno foram realizadas em um espectrômetro de massas Delta Plus da ThermoFinnigan acoplado a um analisador elementar CHNS - EA 1110, no Laboratório de Ecologia Isotópica do Centro de Energia Nuclear na Agricultura, Universidade de São Paulo (CENA/USP). Os valores $\delta^{15} \mathrm{~N}$ e $\delta^{13} \mathrm{C}$ foram expressos em partes por mil (\%) com relação aos padrões internacionais AIR e PDB, respectivamente.

O elemento estrôncio ( $\mathrm{Sr})$ possui quatro isótopos que ocorrem naturalmente, ${ }^{84} \mathrm{Sr}(0.56 \%),{ }^{86} \mathrm{Sr}(9.87 \%)$ e ${ }^{88} \mathrm{Sr}$ $(82.53 \%)$, sendo o quarto deles, ${ }^{87} \mathrm{Sr}$ (7.04\%), um isótopo radiogênico, ou seja, fruto do decaimento radioativo de um radioisótopo mãe, no caso, do rubídio $\left({ }^{87} \mathrm{Rb}\right)$, que leva uma meia-vida de $4.88 \times 10^{10}$ anos para decair em ${ }^{87} \mathrm{Sr}$. Uma vez que depende do decaimento do ${ }^{87} \mathrm{Rb}$, a abundância de ${ }^{87} \mathrm{Sr}$ na geologia local é variável e, para que possa ser comparada em diferentes amostras, é determinada em relação a um isótopo de estrôncio não-radiogênico, o ${ }^{86} \mathrm{Sr}$ (Bentley 2006).

Esta variação, portanto, é chamada de "razão isotópica de estrôncio" $\left({ }^{87} \mathrm{Sr} /{ }^{86} \mathrm{Sr}\right)$, a qual depende da abundância de estrôncio, de rubídio - o que pode variar conforme o tipo de rocha - e da idade da rocha. Assim, unidades geológicas mais antigas e com alta concentração de rubídio, apresentam razões isotópicas ${ }^{87} \mathrm{Sr} /{ }^{86} \mathrm{Sr}$ mais elevadas; ao passo que formações geológicas mais recentes e com baixa concentração de rubídio, apresentam razões isotópicas menores (Herz e Garrison 1998; Bentley 2006: 137; Price, Burton e Bentley 2002: 118). Por meio do intemperismo dos materiais geológicos, o estrôncio presente nas rochas atinge o solo e a água subterrânea, caminho que o leva até a cadeia alimentar e, portanto, ao esqueleto humano, onde substitui o cálcio nos minerais do tecido esquelético (Bentley 2006: 136). Analisando as razões isotópicas de estrôncio de indivíduos sepultados em sítios arqueológicos, portanto, podemos ter acesso à média das assinaturas ${ }^{87} \mathrm{Sr} /{ }^{86} \mathrm{Sr}$ consumidas que, se comparada à assinatura da geologia e outras fontes locais de estrôncio, pode gerar informações sobre migração e mobilidade humana pré-colonial (Price, Burton e Bentley 2002: 118).

Para a determinação das razões isotópicas ${ }^{87} \mathrm{Sr} /{ }^{86} \mathrm{Sr}$ a partir do esmalte dentário, foram analisadas 38 amostras humanas, havendo preferência pelos dentes pré-molares, e 12 amostras de fauna oriundas do próprio sítio. As amostras foram: 1. Higienizadas com água deionizada, escova de dente, sonda exploradora e bisturi; 2 . Imersas em ácido acético 0,5M e colocadas em ultrassom por $20 \mathrm{~min}$; 3. Retiradas em torno de $20 \mathrm{mg}$ de esmalte de cada dente com broca diamantada esférica; 4. Adicionados $2 \mathrm{ml}$ de HNO3 concentrado, sendo as amostras digeridas por 1h; 5 . Dissolvidas em $1 \mathrm{ml}$ de HNO3 $2 \mathrm{M}$ para passagem na coluna de troca iônica preenchida com $80 \mathrm{mg}$ de resina Sr-Spec, onde foram purificadas segundo o protocolo do CPGeo/USP. A composição isotópica foi determinada por meio de Espectrômetro de Massas por Termoionização (TIMS), um TRITON da marca ThermoScientific, no Centro de Pesquisas Geocronológicas, Universidade de São Paulo (CPGeo/USP). Ao longo do ano em que foram realizadas as análises, de janeiro de 2014 a janeiro de 2015 , o valor médio para a razão ${ }^{87} \mathrm{Sr}{ }^{86} \mathrm{Sr}$ do padrão NBS-987 variou entre $0.710233 \pm 0.000022$ e $0.710251 \pm 0.000038$. Os erros das análises foram reportados em $2 \mathrm{~s}$ e forneceram um valor médio de 0,000049 . 


\section{RESULTADOS E DISCUSSÃO}

\section{Isótopos de nitrogênio $\left(\delta^{15} \mathrm{~N}\right)$, carbono $\left(\delta^{13} \mathrm{C}\right)$ e paleodieta}

Os valores $\delta^{15} \mathrm{~N}$ das amostras de colágeno humano analisadas variaram entre 16,3\% e 20,8\%o (amplitude de 4,5\%o), apresentando média de $18,1 \%$, com desvio padrão de $0,98 \%$. O maior valor obtido corresponde ao sepultamento 69 , de uma criança ${ }^{5}$, e o menor valor corresponde ao sepultamento 52 , de indivíduo adulto maduro, do sexo feminino. Os valores $\delta^{13} \mathrm{C}$ variaram entre -12,8\%o e -10,3\%o (amplitude de 2,5\%), apresentando média de -11,5\%, com desvio padrão de 0,7\%o. O maior valor obtido corresponde ao sepultamento 30 , de um indivíduo adulto, do sexo masculino, e o menor valor corresponde ao sepultamento 2, de indivíduo adulto jovem, do sexo masculino $^{6}$ (Gráfico 1).

Os valores $\delta^{15} \mathrm{~N}$ das amostras de colágeno da fauna analisada variaram entre 4,4\%o e 19,3\%o, sendo que o maior valor obtido corresponde ao lobo marinho $\left(19,3 \%\right.$ ) e o menor valor corresponde ao porco do mato $(4,4 \%)$. Os valores $\delta^{13} \mathrm{C}$ variaram entre $-22,9 \%$ e $-11,7 \%$, sendo que o maior valor obtido corresponde ao golfinho $(-11,7 \%$ o $)$ e o menor valor corresponde ao porco do mato $(-22,9 \%)$.

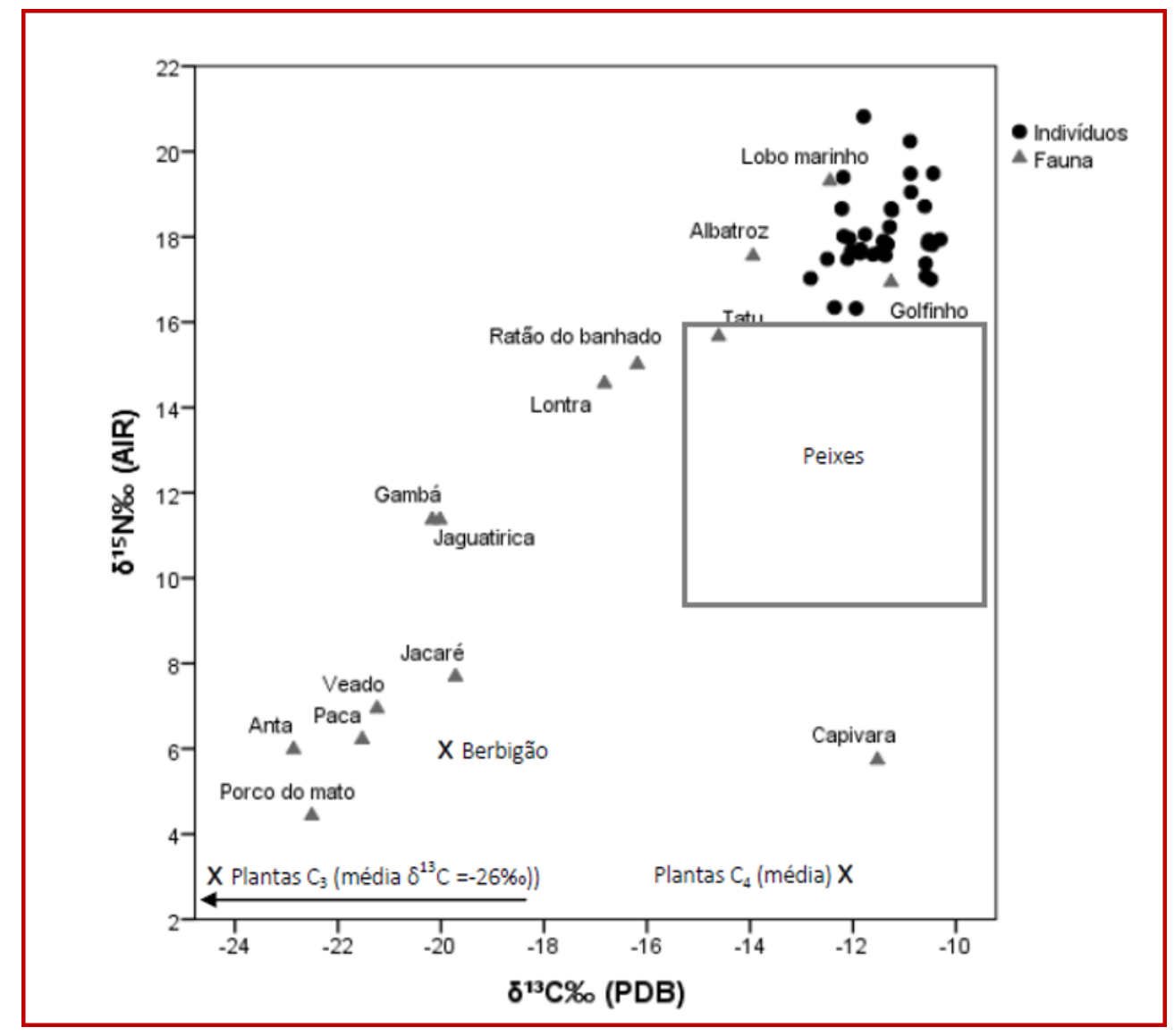

Gráfico 1: Distribuição dos valores $\delta^{13} \mathrm{C}$ e $\delta^{15} \mathrm{~N}$ das amostras humanas e faunísticas analisadas do sítio Armação do Sul, com inserção de dados de peixes, moluscos e plantas de outros autores (Bender 1968; Smith e Epstein 1971; Schoeninger e Moore 1992; De Masi 2001, 2009; Colonese et al. 2014).

5 É importante mencionar que crianças em idade de amamentação têm seus valores $\delta^{15} \mathrm{~N}$ determinados pelo consumo de proteína animal proveniente do leite materno, sendo comumente mais elevados que no restante da população (Katzenberg, Herring e Saunders 1996).

$6 \quad$ Neste artigo são apresentados apenas os resultados gerais e alguns gráficos, tanto das análises de nitrogênio $\left(\delta^{15} \mathrm{~N}\right)$ e carbono $\left(\delta^{13} \mathrm{C}\right)$ quanto das análises de estrôncio ( $\left.{ }^{87} \mathrm{Sr} /{ }^{86} \mathrm{Sr}\right)$. A apresentação mais detalhada dos dados (incluindo informação sobre as amostras) e dos testes estatísticos pode ser conferida em Oppitz (2015). 
Os dados isotópicos de nitrogênio $\left(\delta^{15} \mathrm{~N}\right)$ e carbono $\left({ }^{13} \mathrm{C}\right)$ gerados sugerem que os indivíduos analisados do sítio Armação do Sul apresentavam uma dieta predominantemente marinha e de alto nível trófico, alimentando-se principalmente de peixes. Esses resultados são coerentes com valores $\delta^{15} \mathrm{~N}$ obtidos para populações costeiras pré-coloniais do sul da Califórnia (Walker e DeNiro 1986) e do sul da Patagônia (Borrero e Barberena 2006), bem como para esquimós caçadores de baleias modernos (Schoeninger, DeNiro e Tauber 1983). São coerentes também com os dados provenientes de estudos zooarqueológicos (Bandeira 1992; Klökler 2001, 2008, 2014) e isotópicos (De Masi 2001, 2009; Bastos et al. 2014, 2015; Colonese et al. 2014; Klökler 2014) nos sítios litorâneos catarinenses.

Os vestígios faunísticos, presentes no sítio Armação do Sul e nos demais sítios do litoral catarinense, contudo, sugerem que essas populações estavam também se alimentando de animais terrestres de pequeno e grande porte como pacas, tatus, capivaras, antas, veados, porcos do mato, jaguatiricas, porém em menor quantidade e, como indicam os valores $\delta^{15} \mathrm{~N}$ e $\delta^{13} \mathrm{C}$, com contribuição proporcionalmente pequena na dieta proteica dos indivíduos, se comparada à contribuição dos peixes.

Da mesma forma, a presença de tubérculos carbonizados nos sítios catarinenses (Scheel-Ybert et al. 2003, ver também Scheel-Ybert 2013), aliada à ocorrência de possíveis grânulos de amido de milho, batata doce e carás, em cálculos dentários, bem como fitólitos de gramíneas, palmeiras e de pinhão (Wesolowski 2007, Boyadjian et al. 2016), indicam que os vegetais estavam presentes na dieta dessas populações litorâneas. Embora os peixes fossem a principal fonte de proteínas, os vegetais poderiam ter papel importante como fonte de carboidratos - ou seja, como fonte energética. Nesse sentido, a análise da composição isotópica de carbono dos indivíduos por meio da apatita (Lee-Thorp, Sealy e Van der Merwe 1989) poderia trazer resultados diferentes, uma vez que informaria sobre a dieta total (carboidratos, proteínas e lipídios) e não apenas sobre a dieta proteica como sinaliza o colágeno. Bastos et al. (2015), no entanto, realizaram análises sobre a apatita do esmalte dentário de indivíduos sepultados no sítio Tapera - que, assim como o sítio Armação do Sul, está situado no litoral central catarinense - e os valores $\delta^{13} \mathrm{C}$ obtidos corroboraram os resultados do colágeno, ou seja, não indicaram um grande consumo de plantas.

Em meio à tendência marinha na dieta, alguns indivíduos se destacaram como outliers por combinarem valores $\delta^{13} \mathrm{C}$ e $\delta^{15} \mathrm{~N}$ um pouco menores que os demais, o que poderia estar indicando um consumo maior de plantas $\mathrm{C}_{3}$ e/ou animais terrestres. As razões para esses indivíduos apresentarem uma dieta distinta, contudo, são difíceis de serem inferidas, podendo estar relacionadas a tabus, preferências e restrições em momentos específicos de suas vidas, às suas posições sociais ou, ainda, à passagem de parte de seus últimos anos de vida em meio a uma população com dieta distinta daquela do sítio Armação do Sul. Além disso, duas crianças apresentaram os valores $\delta^{15} \mathrm{~N}$ mais altos do sítio, o que provavelmente se deve ao consumo de leite materno (Katzenberg, Herring e Saunders 1996).

Saindo dessa perspectiva que lida apenas com a tendência isotópica geral do sítio e inserindo os resultados na diacronia (Gráfico 2), é possível observar a existência de diferença significativa entre os valores $\delta^{15} \mathrm{~N}$ dos dois períodos do sítio $(t=2,102, d f=20,944, p=0,048)$, que diminuem de uma média de $+18,3 \%$ para $+17,7 \%$, diferença que está sendo causada principalmente pela diminuição nos valores do grupo masculino. As mulheres mantêm média semelhante ao longo do tempo, descartando-se as outliers.

Quanto aos valores $\delta^{13} \mathrm{C}$, embora eles não mudem significativamente de um período para o outro $(\mathrm{t}=0,174, \mathrm{df}=32$, $\mathrm{p}=0,863$ ), quando os cruzamos com as idades radiocarbônicas obtidas para cada um dos indivíduos datados - o que reduz a amostra para $\mathrm{n}=26$ - obtemos correlação alta e significativa entre as duas variáveis para um nível de confiança de $99 \%$ ( $\mathrm{r}=$ $\left.0,580, \mathrm{r}^{2}=0,34, \mathrm{p}=0,002\right)$. Assim, os valores $\delta^{13} \mathrm{C}$ também mudam ao longo do tempo, tornando-se mais negativos, porém com uma sutileza que faz as diferenças passarem despercebidas pelo teste $t$ de Student, talvez pelo fato de o enriquecimento trófico 
nesses valores ser de apenas 1\%o. Após exclusão do outlier (criança do sepultamento 69), os valores $\delta^{15} \mathrm{~N}$ também apresentam correlação significativa com as datações $\left(r=0,396, r^{2}=0,157, p=0,045\right)$ - porém de grau moderado e apenas para um nível de confiança de $95 \%$ - corroborando o resultado do teste $t$ com uma diminuição nos valores.

A partir do Gráfico 2, é possível também inferir que a dieta dos indivíduos do sexo masculino do sítio Armação do Sul mudou. E mudou de forma que, assim como no período 1 havia indivíduos que se destacavam por apresentar valores $\delta^{15} \mathrm{~N}$ mais altos, no período 2 alguns deles se destacavam por apresentar valores $\delta^{13} \mathrm{C}$ mais altos; ou seja, de uma forma ou de outra, alguns homens sempre se diferenciavam dos demais indivíduos do sexo masculino e dos indivíduos do sexo feminino com relação à dieta. As mudanças observadas nas práticas mortuárias e no sedimento que compõe o sítio, portanto, foram acompanhadas por mudanças na dieta.

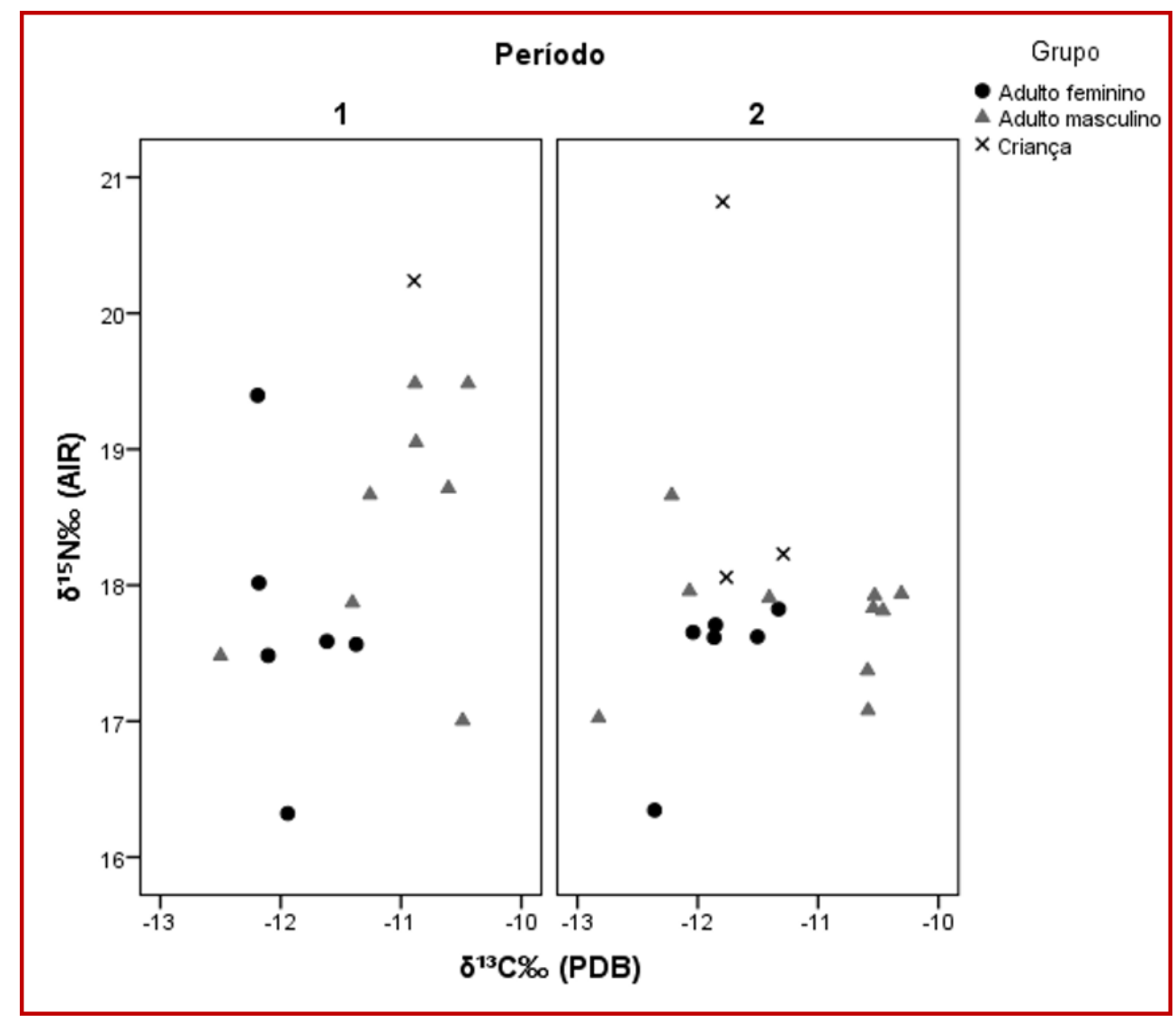

Gráfico 2: Dispersão dos valores $\delta^{13} \mathrm{C}$ e $\delta^{15} \mathrm{~N}$ entre adultos do sexo feminino, adultos do sexo masculino e crianças (sem determinação de sexo) do sítio Armação do Sul.

Fica, contudo, a dúvida: o que teria causado essa mudança nos valores isotópicos? A diminuição no consumo de recursos marinhos de alto nível trófico; a introdução ou aumento no consumo de plantas $\mathrm{C}_{4}$, como o milho; ou, ainda, as duas coisas ao mesmo tempo? Nada é possível afirmar, ainda mais tendo em vista a pequena quantidade de evidências do consumo de milho no registro arqueológico dos sítios conchíferos - com exceção de Wesolowski (2007) e Boyadjian et al. (2016).

Independentemente do motivo da mudança nos valores isotópicos do sítio Armação do Sul, se inserirmos esses dados no contexto local do litoral central de Santa Catarina (Gráfico 3), é possível observar que a mudança tem continuidade em sítios mais recentes como Tapera (Bastos et al. 2015) e Porto do Rio Vermelho II (De Masi 2001). 


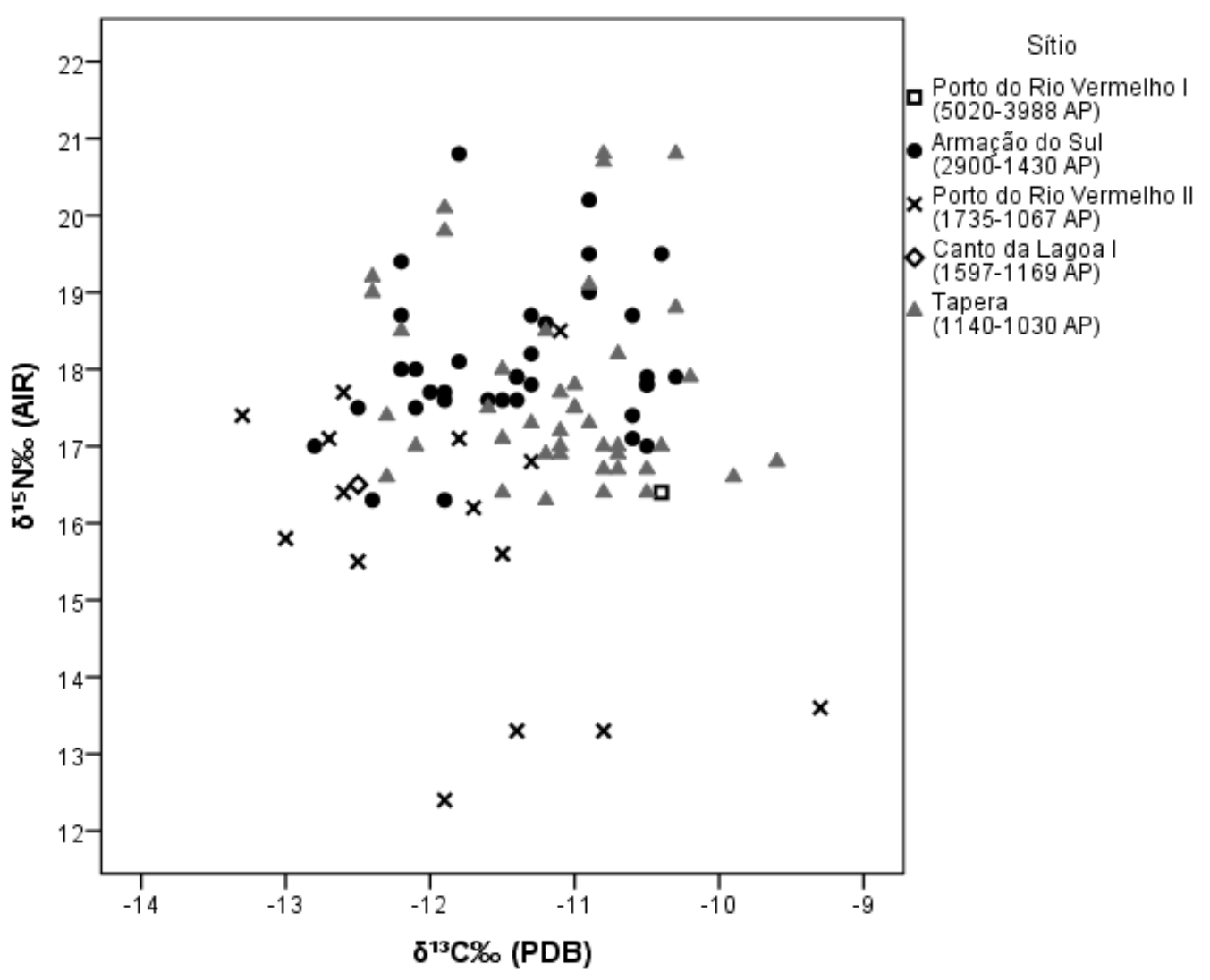

Gráfico 3: Dispersão dos valores $\delta^{13} \mathrm{C}$ e $\delta^{15} \mathrm{~N}$ obtidos para os sítios Tapera (Bastos 2014), Porto do Rio Vermelho I, Porto do Rio Vermelho II, Canto da Lagoa I (De Masi 2001) e Armação do Sul. Os sítios estão dispostos em ordem cronológica na legenda, juntamente com suas idades radiocarbônicas mais antigas e mais recentes (não calibradas).

Ainda com relação ao contexto local, a semelhança observada entre os valores $\delta^{15} \mathrm{~N}$ e $\delta^{13} \mathrm{C}$ dos sítios Armação do Sul e Tapera é extremamente interessante, indicando ser possível haver continuidade histórica entre esses sítios ${ }^{7}$, um sem presença de cerâmica e outro cerâmico. Embora os valores $\delta^{13} \mathrm{C}$ e $\delta^{15} \mathrm{~N}$ do período 2, do sítio da Armação, apresentem diferença significativa com relação aos valores do período 1, eles são significativamente semelhantes em sua distribuição aos valores $\delta^{15} \mathrm{~N}$ da Tapera, de acordo com o teste $U$ de Mann-Whitney $(\mathrm{p}=0,139)^{8}$. E o mesmo serve para os valores $\delta^{13} \mathrm{C}$, de acordo com o teste $t(\mathrm{t}=-1,767, \mathrm{df}=59, \mathrm{p}=0,082)$ em um nível de confiança de 95\%. Igualmente interessantes são as diferenças observadas nos valores desses dois sítios, que se situam em uma mesma localidade, com relação ao sítio Porto do Rio Vermelho II (De Masi 2001), situado em outra localidade do litoral central. Os indivíduos do sítio Armação do Sul se diferem daqueles do sítio Porto do Rio Vermelho II com relação aos valores $\delta^{15} \mathrm{~N}(\mathrm{t}=4,031, \mathrm{df}=18,950, \mathrm{p}=0,001)$, que são mais altos, sendo os valores $\delta^{13} \mathrm{C}$ semelhantes $(\mathrm{t}=1,289, \mathrm{df}=32, \mathrm{p}=0,207)$; e os indivíduos do sítio Tapera se diferem tanto com relação aos valores $\delta^{15} \mathrm{~N}$ $\left(\mathrm{p}=0,001\right.$, teste Mann-Whitney), que são mais altos, quanto com relação aos valores $\delta^{13} \mathrm{C}(\mathrm{t}=-3,135, \mathrm{df}=55, \mathrm{p}=0,003)$, que são também maiores.

Tendo em vista que os sítios Tapera e Armação do Sul se situam no sul da Ilha de Santa Catarina, enquanto o sítio Porto do Rio Vermelho II se encontra no entorno da Lagoa da Conceição, no leste da Ilha, essas apontam para a possibilidade de haver diferenças no modo de vida das populações associadas a diferentes conjuntos de sítios em diferentes partes do litoral

7 Para uma discussão sobre a continuidade histórica entre sítios conchíferos com e sem cerâmica, bem como apresentação de mais indicadores para a continuidade entre Armação do Sul e Tapera, ver Oppitz (2015).

8 Foi utilizado um teste não paramétrico devido à ausência de normalidade nos valores $\delta^{15} \mathrm{~N}$ da amostra da Tapera. 
central.Mesmo havendo pouca chance de serem contemporâneos, os sítios Armação do Sul e Tapera se aproximam mais entre si do que com o sítio Porto do Rio Vermelho II, que é provavelmente contemporâneo dos dois.

Ao mesmo tempo, contudo, as populações dos três sítios parecem estar modificando suas dietas numa mesma direção (deslocamento para baixo e para a direita do gráfico), e, como conjunto de sítios do litoral central, apresentam diferenças com relação aos sítios de outras porções do litoral catarinense, como Forte Marechal Luz (Bastos et al. 2014), no litoral norte, e Jabuticabeira II e Galheta IV (Colonese et al. 2014), no litoral sul (Tabela 1 e Gráfico 4). Diferenças não tanto na composição da dieta em si, que é predominantemente marinha em todos os sítios analisados, mas na forma como ela muda - ou não muda - ao longo do tempo. Nesse sentido, foi observada diminuição nos valores $\delta^{15} \mathrm{~N}$ e aumento nos valores $\delta^{13} \mathrm{C}$ no litoral central (alteração em direção ao consumo de plantas $\mathrm{C}_{4}$ e/ou diminuição no consumo de recursos marinhos de alto nível trófico); aumento nos valores $\delta^{15} \mathrm{~N}$ e diminuição nos valores $\delta^{13} \mathrm{C}$ no litoral norte (alteração em direção ao consumo de recursos terrestres e plantas $\mathrm{C}_{3}$ ); e aparente ausência de mudança no litoral sul.

Tabela 1: Média dos valores $\delta^{13} \mathrm{C}$ e $\delta^{15} \mathrm{~N}$ obtidos para os sítios Tapera (Bastos 2014), Porto do Rio Vermelho II (De Masi 2001) e Armação do Sul, do litoral central; Forte Marechal Luz (Bastos 2014), do litoral norte; e Jabuticabeira II e Galheta IV (Colonese et al. 2014), do litoral sul.

\begin{tabular}{|c|c|c|c|c|c|c|}
\hline Porção litorânea & Sítio & Período & média $\delta^{15} \mathrm{~N} \%$ & média $\delta^{13} \mathrm{C} \%$ & $\mathbf{N}$ & Referência \\
\hline \multirow{2}{*}{ Litoral Norte } & Forte Marechal Luz (s/ cerâmica) & Antigo & $15,5 \pm 0,7$ & $-12,0 \pm 1,2$ & 7 & Bastos (2014) \\
\hline & Forte Marechal Luz (c/ cerâmica) & Tardio & $15,9 \pm 1,0$ & $-13,4 \pm 1,3$ & 5 & Bastos (2014) \\
\hline \multirow{4}{*}{ Litoral Central } & Armação do Sul (período 1) & Antigo & $18,3 \pm 1,1$ & $-11,4 \pm 0,7$ & 16 & Oppitz (2015) \\
\hline & Armação do Sul (período 2) & Tardio & $17,7 \pm 0,5$ & $-11,4 \pm 0,8$ & 19 & Oppitz (2015) \\
\hline & Porto do Rio Vermelho II & Tardio & $15,8 \pm 1,8$ & $-11,8 \pm 1,0$ & 15 & De Masi (2001) \\
\hline & Tapera & Tardio & $17,7 \pm 1,3$ & $-11,1 \pm 0,7$ & 42 & Bastos (2014) \\
\hline \multirow{2}{*}{ Litoral Sul } & Jabuticabeira II & Antigo & $17,4 \pm 1,6$ & $-11,5 \pm 1,5$ & 47 & Colonese et al. (2014) \\
\hline & Galheta IV & Tardio & $17,4 \pm 0,6$ & $-11,4 \pm 1,2$ & 7 & Colonese et al. (2014) \\
\hline
\end{tabular}

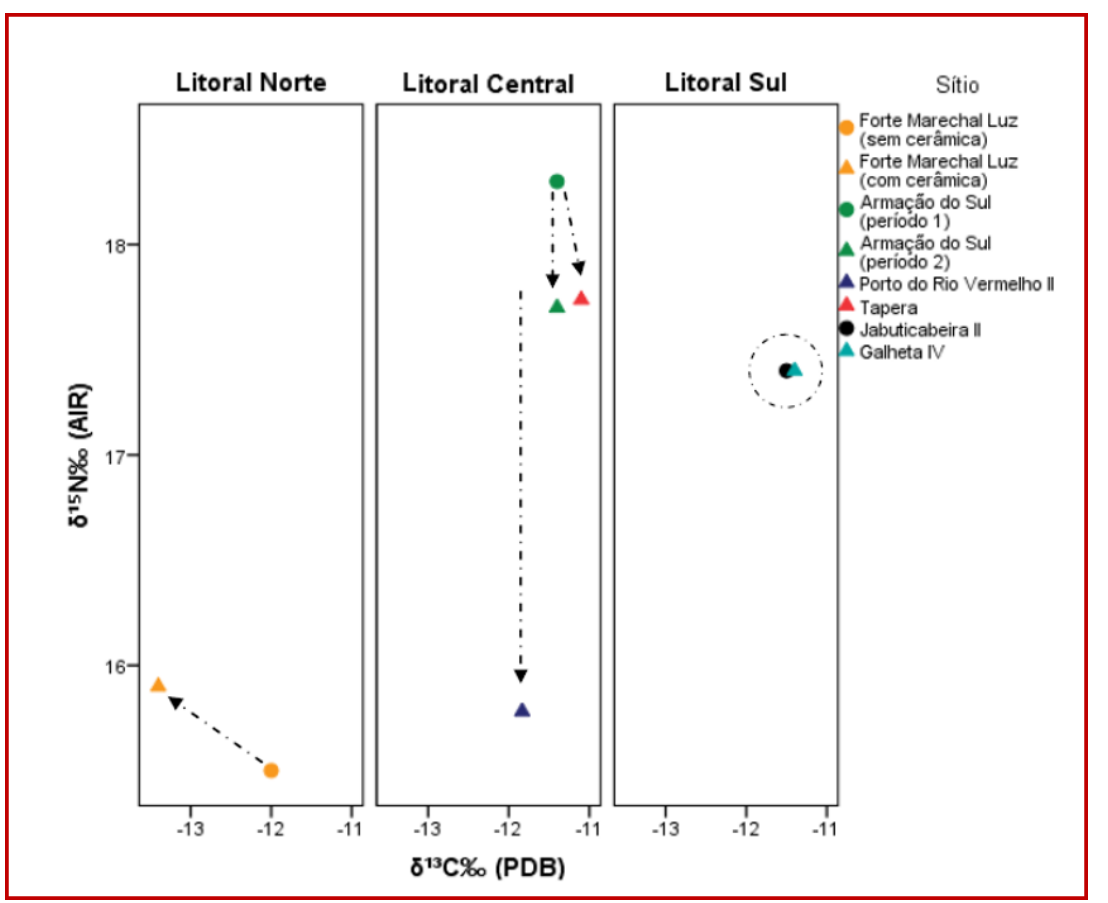

Gráfico 4: Dispersão das médias e representação da direção da mudança ao longo do tempo nos valores $\delta^{13} \mathrm{C}$ e $\delta^{15} \mathrm{~N}$ dos sítios do litoral central [Tapera (Bastos 2014), Porto do Rio Vermelho II (De Masi 2001) e Armação do Sul], do litoral norte [Forte Marechal Luz (Bastos et al. 2014)] e do litoral sul [Jabuticabeira II e Galheta IV (Colonese et al. 2014)]. Os círculos representam os sítios ou períodos mais antigos (>2500-2000 anos AP) e os triângulos representam os sítios mais tardios $(<2500-2000$ anos AP). 
Adentrando o contexto maior dos sítios conchíferos do litoral catarinense como um todo, portanto, os dados indicam que a mudança na dieta possivelmente tomou direções distintas nas diferentes porções litorâneas, desenrolando-se diferentemente nos diferentes contextos locais.

Quando consumimos ou servimos um alimento não estamos apenas manipulando um objeto, mas transmitindo uma situação (Barthes 1979, Douglas 1972). A alimentação não se trata apenas de necessidade, mas de uma necessidade estruturada e estruturante. A comida, assim, pode ser considerada duplamente corpórea, uma vez que participa tanto na criação da pessoa física quando da pessoa social (Atalay e Hastorf 2006).

Não existem distinções naturais, todas as formas de categorização precisam ser construídas e objetivadas (Bourdieu 1989) e, em sua trivialidade e pretensão à naturalidade, a dieta e tudo o mais que é relativo à alimentação - como as técnicas de preparo e modos de servir - aparecem como meios potentes de produção e reprodução de distinções sociais. Norbert Elias (1939), por exemplo, mostra-nos como, em tempos de transição entre a idade média e a idade moderna, a etiqueta e os modos à mesa foram fundamentais na internalização e modulação da nova estrutura de relações interpessoais - cada vez mais contidas - que estava em formação, servindo também na diferenciação da aristocracia absolutista emergente com relação à nobreza feudal decadente e às classes inferiores. Assim, também, o consumo de determinados alimentos por determinados grupos e os tabus que permeiam hábitos alimentares - como o filé pelas classes superiores e as vísceras pelas classes inferiores, ou o tabu da sociedade moderna ocidental com relação aos cachorros (Sahlins 1976) - são importantes meios de veiculação de identidades.

No sítio Armação do Sul, os valores $\delta^{15} \mathrm{~N}$ do primeiro período revelaram uma dieta de maior nível trófico para os indivíduos do sexo masculino. O que exatamente o consumo de recursos de nível trófico mais elevado ou menos elevado poderia significar para essas populações, não sabemos, mas temos aí uma diferença clara na dieta de homens e mulheres que, com certeza, não se deu naturalmente, sendo resultante de estruturas de relações pré-estabelecidas e reprodutora dessas relações. Vale dizer que essa diferenciação com relação ao nível trófico da dieta, com os homens apresentando valores $\delta^{15} \mathrm{~N}$ e $\delta^{13} \mathrm{C}$ mais elevados e mais heterogêneos, é bastante corrente em diferentes contextos ao redor do mundo, sendo sempre interpretada como indicação de acesso diferenciado aos recursos, nesse caso, de maior acesso a fontes de proteínas ricas em $\delta^{15} \mathrm{~N}$ por parte dos indivíduos masculinos (Larsen 2015[1997]).

E além da distinção sexual, no caso do sítio Armação do Sul os resultados apontam também para distinção entre grupos de indivíduos do sexo masculino, distinção esta que encontra correspondência na distribuição espacial dos sepultamentos (cf. Oppitz 2015). No período 1, a maior parte dos indivíduos masculinos apresenta valores $\delta^{15} \mathrm{~N}$ e $\delta^{13} \mathrm{C}$ mais elevados e estão concentrados na porção sul da área escavada. As exceções são os sepultamentos 71 e 74 , com valores $\delta^{15} \mathrm{~N}$ e $\delta^{13} \mathrm{C}$ menores - como os do grupo feminino - e situados em espaço diametralmente oposto aos demais, na porção norte; e o sepultamento 37 , que está situado na porção sul, porém com valores $\delta^{15} \mathrm{~N}$ mais elevados, valores $\delta^{13} \mathrm{C}$ menores e com datação mais antiga que os demais, provavelmente sendo o primeiro sepultamento do sítio. No período 2, a maior parte dos indivíduos apresenta valores $\delta^{15} \mathrm{~N}$ semelhantes aos das mulheres ou menores, porém valores $\delta^{13} \mathrm{C}$ mais elevados, e se dividem de forma que os indivíduos de datação mais antiga se situam na porção sudeste da área escavada e os sepultamentos mais recentes na porção norte. As exceções são os sepultamentos $61 \mathrm{e} \mathrm{78,} \mathrm{com} \mathrm{valores} \delta^{15} \mathrm{~N}$ e $\delta^{13} \mathrm{C}$ semelhantes aos das mulheres e situados na porção noroeste, o sepultamento 2, com valores $\delta^{15} \mathrm{~N}$ e $\delta^{13} \mathrm{C}$ menores e o sepultamento 5 , com valor $\delta^{15} \mathrm{~N}$ maior e valor $\delta^{13} \mathrm{C}$ menor, estes dois últimos estando situados na porção norte e apresentando datações mais recentes que os demais. 
Tanto no período 1 quanto no período 2, portanto, há um grupo de indivíduos do sexo masculino que se assemelha às mulheres com relação à dieta e, ao mesmo tempo, um grupo que se diferencia, ora consumindo recursos de maior nível trófico (período 1), ora consumindo maior quantidade de recursos terrestres e talvez até plantas $\mathrm{C}_{4}$ ou animais que delas se alimentam, como a capivara (período 2). Coincidentemente ou não, os indivíduos com dieta semelhante à das mulheres estão sepultados sempre na porção norte-noroeste da área escavada, no mesmo local onde há uma grande concentração de sepultamentos de crianças do segundo período 9 .

As diferenças observadas podem estar associadas tanto à posição desses indivíduos na sociedade e questões de $s t a-$ tus, quanto ao seu pertencimento a grupos de parentesco distintos. Mais uma vez, contudo, é difícil inferir o que uma dieta de maior ou menor nível trófico e o consumo maior ou menor de recursos $\mathrm{C}_{4}$ - se de fato for o caso - pode significar no contexto dessas relações de status e parentesco, para além, claro, do fato de estarem refletindo e produzindo distinções sociais.

Embora entre os indivíduos consumidores de recursos de nível trófico mais elevado (período 1) e de, talvez, maior quantidade de recursos $\mathrm{C}_{4}$ (período 2), estejam alguns daqueles que apresentaram maior número de acompanhamentos funerários, enquanto aqueles indivíduos com dieta semelhante à do grupo feminino apresentaram número menor de acompanhamentos (Oppitz 2015), não é possível estabelecer correlações seguras entre essas variáveis, uma vez que os sepultamentos desses últimos são todos incompletos ${ }^{10}$. Por outro caminho, levando em consideração a distribuição espacial, poderíamos arriscar a sugestão de que os indivíduos de dieta próxima à das mulheres teriam um status, de alguma forma, vinculado às crianças, devido ao espaço que ocupam na área escavada do sítio, junto às crianças da extremidade norte-noroeste, mas para isso precisaríamos de mais dados.

Curiosamente, não há diferenciação interna no grupo feminino, este apresentando valores constantes e bastante homogêneos tanto do ponto de vista sincrônico quanto do ponto de vista diacrônico. Apesar da presença de algumas mulheres consideradas outliers, estas não formam conjuntos coerentemente diferenciados como formam os indivíduos masculinos e, tampouco, apresentam correlações com dados relativos às práticas mortuárias (acompanhamentos funerários ou distribuição espacial); logo, podem ser entendidas somente em termos de possíveis tabus, preferências e restrições alimentares (como foram entendidos todos os indivíduos outliers adultos do sítio, femininos ou masculinos), sem extrapolações ou inferências relativas à distinção social. Isso não deve significar ausência de distinções entre os indivíduos do sexo feminino, apenas que essas distinções não estavam refletindo em suas dietas proteicas, pelo menos não de forma perceptível nos valores isotópicos de nitrogênio e carbono do colágeno.

A atuação da dieta na produção e reprodução de distinções sociais entre os indivíduos do sítio Armação do Sul, distinções tanto de ordem sexual quanto de status ou parentesco, é fortemente indicada, e mostra como a análise de isótopos de nitrogênio e carbono, se associada a uma cronologia fina, pode revelar não somente a forma como as coisas mudam ao longo do tempo, mas também aspectos dessa dimensão sutil das relações humanas, que é a criação de distinções e identidades entre práticas e representações, algo que pode ser aprofundado em estudos futuros.

Uma vez reconhecido esse potencial com relação à evidenciação de distinções internas às sociedades, a análise pode também ser estendida para a observação do papel da dieta no estabelecimento de fronteiras e na formação de identidades entre sítios que pertencem a um mesmo contexto local, como o litoral central de Santa Catarina, ou entre diferentes localidades de

\footnotetext{
9 É importante salientar aqui que o sítio Armação do Sul tem uma área total estimada por Rohr em $2000 \mathrm{~m}^{2}$, porém teve somente $269 \mathrm{~m}^{2}$ escavados $-85 \mathrm{~m}^{2}$ na primeira etapa e $184 \mathrm{~m}^{2}$ na segunda, com $10 \mathrm{~m}$ de distância entre as duas áreas. Além disso, a análise da distribuição espacial dos sepultamentos em Oppitz (2015) foi realizada com base somente nos indivíduos datados, pouco mais de 30\% da amostra total. A inclusão de todos os sepultamentos escavados, distribuídos em lâminas definidas a partir de suas profundidades, poderia tanto reafirmar quanto complexificar ou alterar o que foi observado.
}

10 Em geral, costelas e vértebras ou extremidades dos membros ou membros inferiores ausentes (ou não escavados) (Schmitz et al. 1992). 
um contexto regional maior, como o litoral catarinense. Os dados apresentados indicam a existência de diferenças no contexto do litoral central e entre diferentes porções do litoral catarinense, porém é necessário um maior número de sítios analisados para o aprofundamento dessas questões.

Por fim, cabe destacar que, de acordo com os resultados obtidos, pelo menos no litoral central a dieta começou a mudar por volta de 2500 anos AP, muito tempo antes do aparecimento da cerâmica no local - que se deu por volta de $1330 \pm 30$ anos AP, no sítio Tapera. Como a cerâmica foi utilizada principalmente no processamento de peixes (Hansel 2006, Colonese et al. 2014), ela deve ter tido um importante papel não na alteração daquilo que estava sendo consumido, mas na forma como estava sendo consumido, aparecendo como moduladora de novas formas de processar, cozinhar, servir, estocar alimentos e gerenciar o tempo (Atalay e Hastorf 2006), e, assim, interferindo ativamente no comportamento humano e nas relações interpessoais (Gosden 2005).

\section{Isótopos de estrôncio $\left({ }^{87} \mathrm{Sr}{ }^{\beta 6} \mathrm{Sr}\right)$ e mobilidade}

Os valores da razão isotópica ${ }^{87} \mathrm{Sr} /{ }^{86} \mathrm{Sr}$ das amostras de esmalte dentário humano analisadas, variaram entre 0,70951 e 0,71097 (amplitude de 0,00146), apresentando média de 0,71, com desvio padrão de 0,00033. O maior valor obtido corresponde ao sepultamento $2(0,71097)$, de indivíduo adulto jovem, do sexo masculino, e o menor valor corresponde ao sepultamento $46(0,70951)$, de indivíduo adulto, também do sexo masculino.

Os valores da razão ${ }^{87} \mathrm{Sr} /{ }^{86} \mathrm{Sr}$ do esmalte dentário da fauna analisada, variaram entre 0,70918 e 0,71959 (amplitude de 0,01041$)$, apresentando média de 0,7127 , com desvio padrão de 0,00402 . O maior valor obtido $(0,71959)$ corresponde ao porco do mato e o menor valor corresponde à ostra (0,70918).

Frente aos dados isotópicos de estrôncio $\left({ }^{87} \mathrm{Sr} /{ }^{86} \mathrm{Sr}\right.$ ) gerados (Gráfico 5), está claro que possivelmente nenhum dos indivíduos analisados do sítio Armação do Sul passou seus primeiros anos de vida em regiões de disponibilidade isotópica muito distinta daquela encontrada no litoral de Santa Catarina, como o interior do continente, a encosta da serra ou o planalto, e as análises de $\delta^{15} \mathrm{~N}$ e $\delta^{13} \mathrm{C}$ nos permitem afirmar, também, que todos eles passaram seus últimos anos de vida no litoral, alimentando-se sobretudo de recursos marinhos.

Isso significa que as mudanças observadas no sítio Armação do Sul provavelmente não estão relacionadas à incorporação de indivíduos não locais provenientes do interior, mesmo resultado obtido por Bastos et al. (2015) com relação à presença de cerâmica no sítio Tapera que, assim como o sítio Armação do Sul, situa-se no litoral central de Santa Catarina. É possível, no entanto, que tais mudanças estejam relacionadas à incorporação de indivíduos provenientes de regiões litorâneas próximas.

Os valores das assinaturas isotópicas de estrôncio dos indivíduos analisados do sítio Armação do Sul, aumentaram progressivamente desde o início da ocupação do sítio, conforme nos indica a correlação significativa $(p=0,006)$ existente entre os dados de ${ }^{87} \mathrm{Sr} /{ }^{86} \mathrm{Sr}$ e as datações radiocarbônicas (Gráfico 6). As assinaturas dos indivíduos aumentaram de forma sutil e gradual ao longo do tempo, com coeficiente de correlação de Pearson (r) de 0,568 e coeficiente de determinação $\left(\mathrm{r}^{2}\right)$ de 0,323 , indicando que $32 \%$ dos valores isotópicos podem ser explicados pelas datações. Há também uma tendência à maior variação nas razões ${ }^{87} \mathrm{Sr} /{ }^{86} \mathrm{Sr}$ entre os indivíduos mais tardios (Gráfico 7).

Ao considerarmos todos os indivíduos analisados - e não apenas os 22 que foram analisados para ${ }^{87} \mathrm{Sr} /{ }^{86} \mathrm{Sr}$ e também datados - comparando aqueles pertencentes ao período 1 com aqueles pertencentes ao período 2 , o progressivo aumento dos valores e da variação das razões isotópicas se faz ainda mais evidente (Gráfico 8). Há diferença significativa para um nível de confiança de $95 \%$ entre a média dos valores do primeiro período $(0,70982)$ e a média dos valores do segundo período 


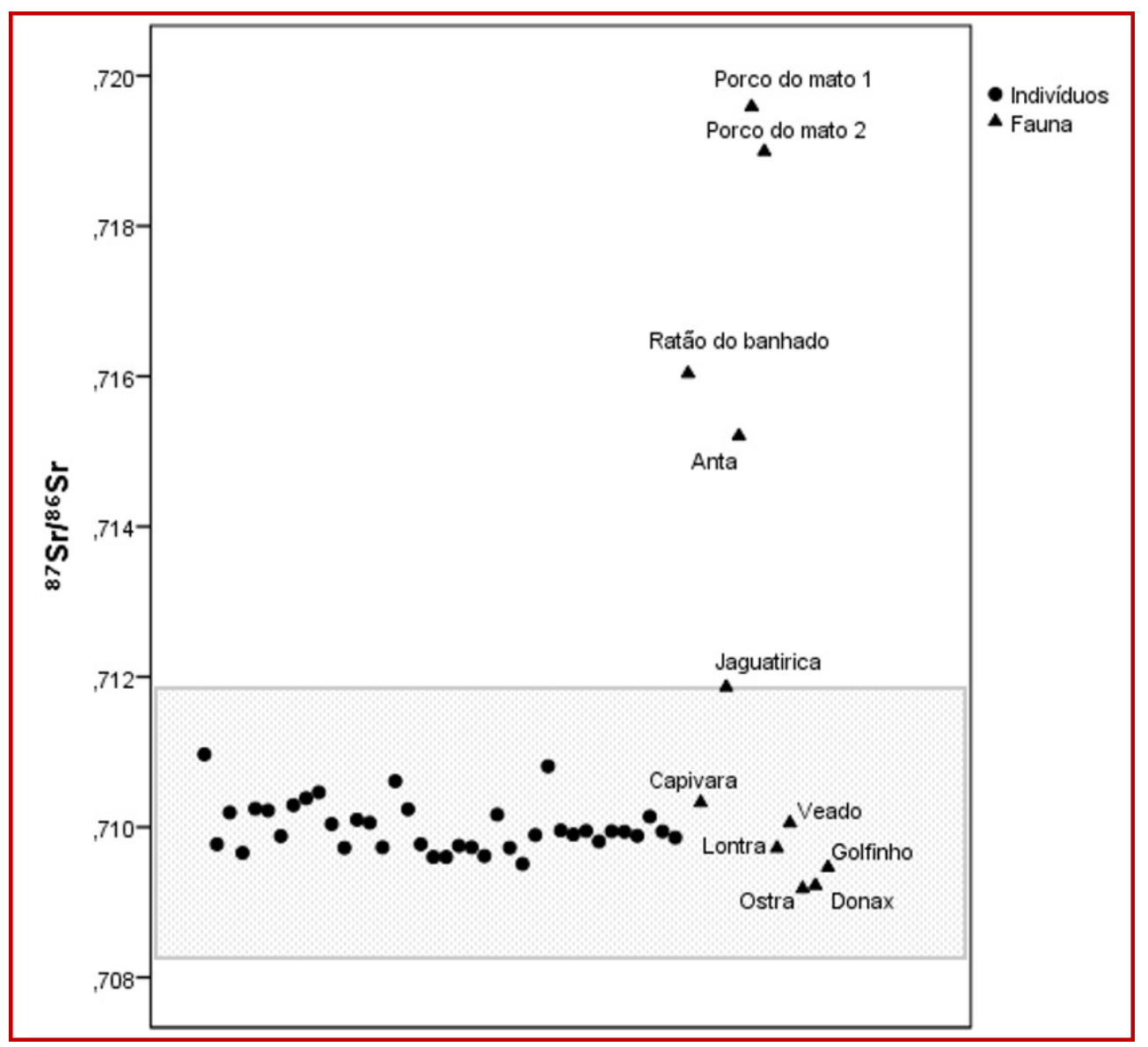

Gráfico 5: Dispersão dos valores isotópicos ${ }^{87} \mathrm{Sr} /{ }^{86} \mathrm{Sr}$ obtidos para a fauna e os indivíduos analisados do sítio Armação do Sul. O quadro cinza representa o alcance da assinatura local biologicamente disponível (0,7081 a 0,7118).

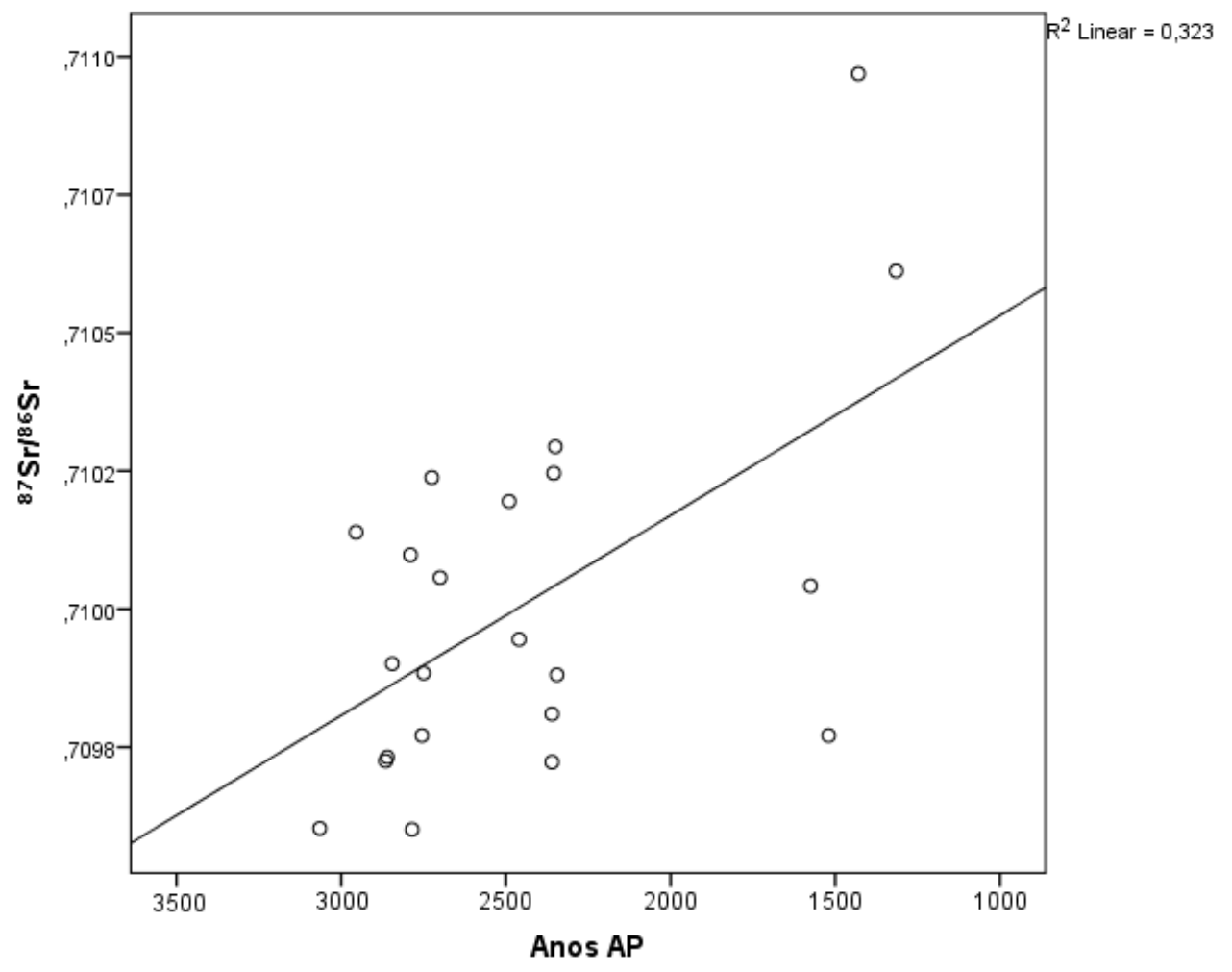

Gráfico 6: Gráfico representando a correlação entre a razões ${ }^{87} \mathrm{Sr} /{ }^{86} \mathrm{Sr}$ e as datações radiocarbônicas. 
(0,71013), com $\mathrm{p}=0,002$ (teste $t$ de Student). Com relação à variação dos valores, os coeficientes de variação de Pearson $(\mathrm{CVp})$ nos mostram que enquanto as assinaturas ${ }^{87} \mathrm{Sr} /{ }^{86} \mathrm{Sr}$ dos indivíduos do período 1 desviam $0,028 \%$ da média, as assinaturas do período 2 apresentam desvio de $0,046 \%$ e, portanto, maior dispersão.

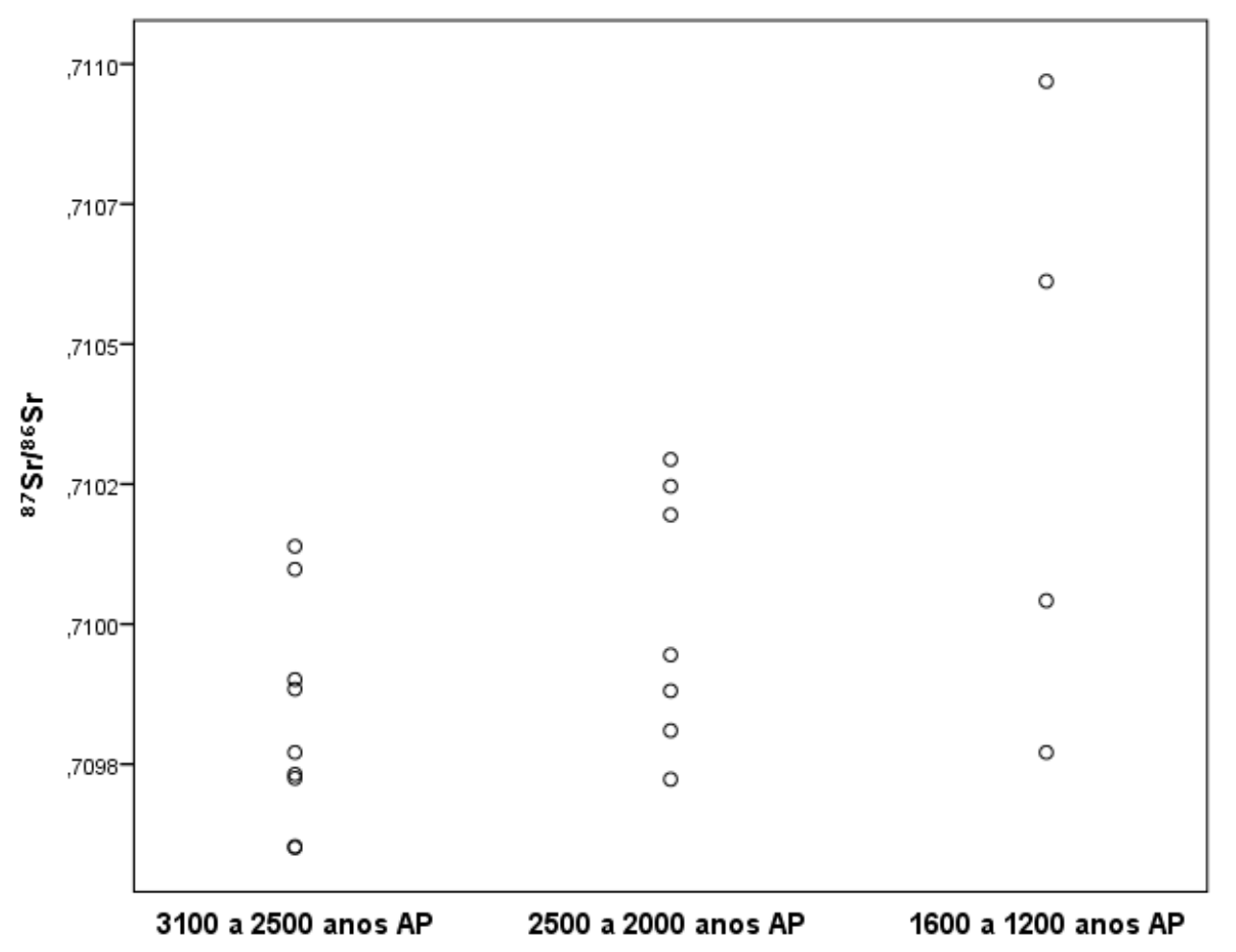

Gráfico 7:Representação da dispersão dos valores ${ }^{87} \mathrm{Sr} /{ }^{86} \mathrm{Sr}$ nos diferentes momentos de ocupação do sítio.

O aumento progressivo dos valores poderia ser explicado por uma mudança gradual da dieta, a qual estaria se tornando mais terrestre ao longo do tempo, como indicado pelas análises isotópicas de carbono e nitrogênio. Acontece que essas análises foram realizadas a partir do colágeno dos ossos, dizendo respeito à dieta dos últimos anos de vida dos indivíduos, enquanto as análises de ${ }^{87} \mathrm{Sr} /{ }^{86} \mathrm{Sr}$ foram realizadas a partir do esmalte dentário, dizendo respeito à assinatura isotópica dos indivíduos na infância, o que inviabiliza o estabelecimento de correlações. O aumento na variação dos valores, por sua vez, seria mais bem explicado por uma expansão nas relações entre populações de regiões litorâneas próximas, com a incorporação de indivíduos provenientes dessas regiões pela população do sítio da Armação do Sul.

De fato, é possível que alguns indivíduos sepultados no sítio sejam provenientes de localidades litorâneas próximas e, em algum momento de suas vidas tenham migrado para a Ilha de Santa Catarina. Embora todos os valores ${ }^{87} \mathrm{Sr} /{ }^{86} \mathrm{Sr}$ obtidos para o esmalte dentário humano estejam de acordo com a assinatura local biologicamente disponível, indicada pela fauna analisada, a presença de outliers e valores desviantes da tendência normal aponta para essa possibilidade.

Quando os resultados são abordados a partir de uma perspectiva geral de longa duração - que lida com a tendência isotópica do sítio ao longo de seus mais de 1000 anos de ocupação - apenas o indivíduo 2 aparece como outlier. Curiosamente, esse é justamente o indivíduo que apresenta evidência de violência, com uma ponta cravada em sua quarta vértebra lombar (Lessa e Scherer 2008). Ao aproximarmos o olhar para momentos cronológicos específicos, porém, percebemos que o indivíduo 49 também desponta como outlier, mas somente dentro do conjunto de valores do primeiro período de ocupação do sítio. Isso chama atenção para a questão colocada por Wright (2005) quanto à possibilidade de indivíduos não locais es- 
tarem incluídos nas extremidades da distribuição normal. Reforça também a ideia de que indivíduos não locais, provenientes de regiões geológicas parecidas, podem estar inseridos dentro da faixa de distribuição da assinatura biológica local, passando despercebidos.

Como os valores ${ }^{87} \mathrm{Sr} /{ }^{86} \mathrm{Sr}$ que desviam da tendência central se destacam por serem mais elevados que os demais, somos levados a supor que os indivíduos potencialmente não locais teriam origem no próprio litoral central, em localidades onde a presença de formações geológicas mais antigas, do Proterozóico e Arqueano, poderia estar elevando as assinaturas isotópicas.

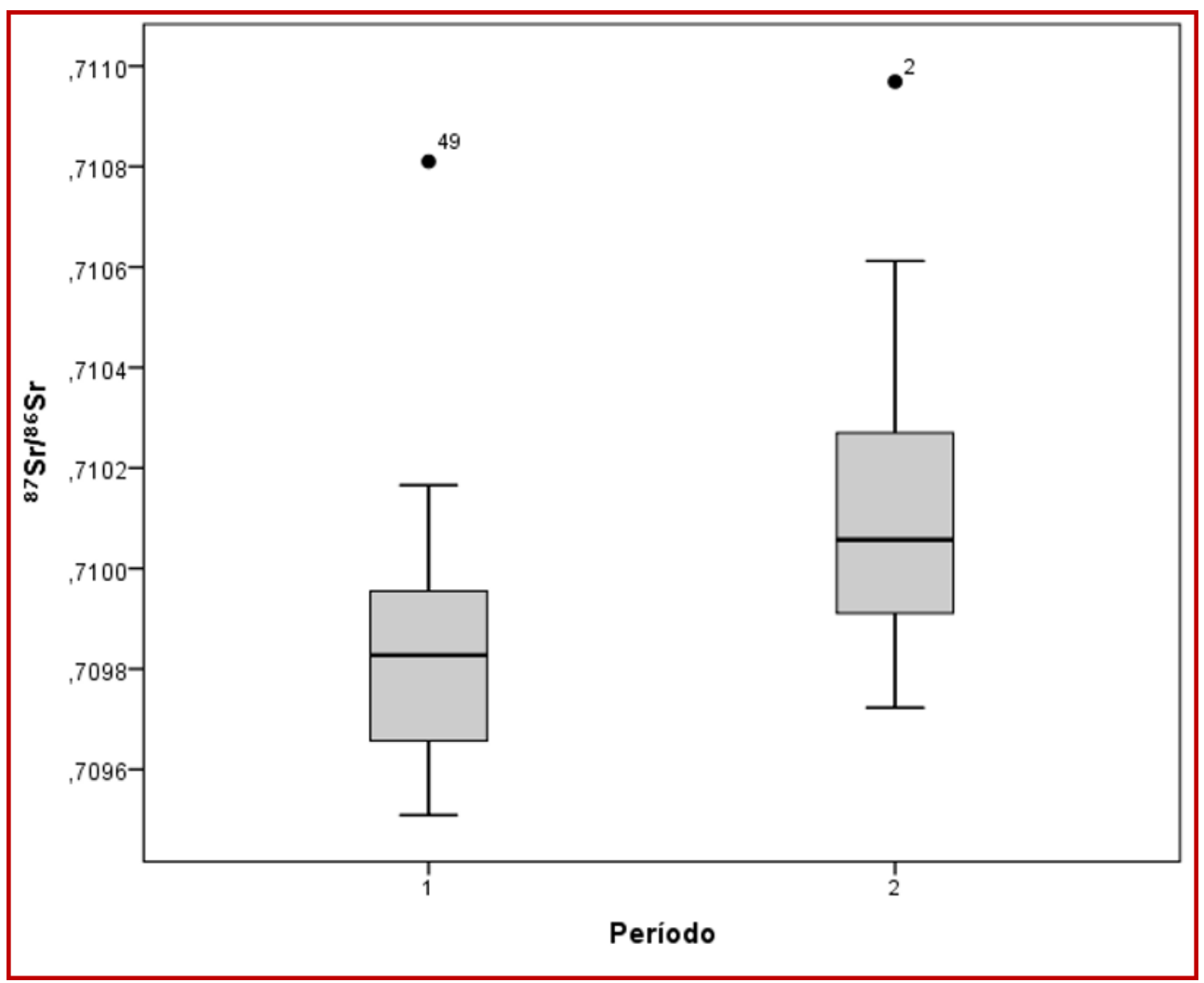

Gráfico 8: Boxplot das razões isotópicas ${ }^{87} \mathrm{Sr} /{ }^{86} \mathrm{Sr}$ obtidas para os indivíduos pertencentes ao período 1 (sepultados na areia marrom e/ou datado entre 3100 e $2500 \mathrm{AP}$ ) e ao período 2 (sepultados na terra preta e/ou datado entre 2500 e $1200 \mathrm{AP}$ ).

Inserindo os resultados obtidos para o sitio Armação do Sul no contexto local do litoral central de Santa Catarina (ver representação dos dados de Armação do Sul e Tapera no Gráfico 9), é possível observar que as médias dos valores ${ }^{87} \mathrm{Sr} /{ }^{86} \mathrm{Sr}$ dos sítios Armação do Sul e Tapera (Bastos et al. 2015) apresentam diferença significativa para um nível de confiança de 95\%, com $\mathrm{p}=0$ (teste $t$ de Student), sendo que o sítio Tapera conta com valores mais elevados. Há também um visível aumento na variação das razões, confirmado pelo cálculo dos coeficientes de variação $(\mathrm{CVp})$, com os valores de Armação do Sul desviando $0,042 \%$ da média e os de Tapera desviando 0,078\%. Essas diferenças provavelmente não são explicadas pela geologia, uma vez que ambos os sítios estão assentados sobre depósitos quaternários, com proximidade de granitos alcalinos das suítes intrusivas Pedras Grandes e Pultono Vulcânica Cambirela, a não ser que as populações em questão estivessem caçando, coletando recursos e utilizando fontes de água de áreas diferentes, com geologia muito distinta daquela que caracteriza seu entorno.

No sítio Tapera, a elevada variação dos valores se dá principalmente entre os indivíduos do sexo feminino, o que levou Bastos et al. (2015) a levantarem a hipótese da virilocalidade, como foi sugerido por Hubbe (2009) para os sítios cerâmicos mais tardios. O sítio Armação do Sul, por sua vez, parece apresentar uma maior variação entre os indivíduos do 
sexo masculino no período 1 e uma equiparação no período 2, causada por um aumento grande na variação das mulheres e aumento menor na variação dos homens. Para interpretar esse quadro, podemos também seguir a proposta de Hubbe (2009) e considerar a possibilidade de que o período 1 teria sido marcado pela uxorilocalidade e o período 2 por uma transição de um padrão uxorilocal para um padrão virilocal; ou, então, de que ambos os períodos representariam essa transição, uma vez que a distribuição dos dados não deixa nada muito claro.

Em sua análise dos marcadores de estresse músculo-esquelético, Scherer et al. (2015) observaram que a parcela feminina do sítio Armação do Sul não parece ter realizado atividades regulares que envolvessem deslocamentos para longe de seu núcleo habitacional, enquanto que o grupo feminino do sítio Tapera apresentou casos compatíveis com deslocamentos mais frequentes e/ou em maiores distâncias. Esses resultados podem estar simplesmente apontando para padrões de mobilidade e/ou realização de atividades distintas pelas mulheres dos sítios em questão, mas não pode ser descartada a possibilidade de indicarem passagem de um padrão de residência uxorilocal para um padrão virilocal, em tempos mais tardios.

Frente a esses dados relativos às diferenças entre Armação do Sul e Tapera, e partindo da ideia de continuidade histórica entre os sítios conchíferos com e sem cerâmica, podemos pensar então que o aumento dos valores isotópicos ${ }^{87} \mathrm{Sr} /{ }^{86} \mathrm{Sr}$ observado desde o início da formação do sítio Armação do Sul faz parte de um processo que continua no sítio da Tapera (Bastos et al. 2015), pois este sítio apresenta razões que ora se sobrepõem aos daquele e ora são ainda mais altas. E o mesmo serve para o aumento na variação dos valores no sítio Armação do Sul, que parece prenunciar a variação ainda maior que teria lugar no momento seguinte, representando o início de um processo que teria continuidade em sítios cerâmicos como Tapera.

A diferença entre a média dos valores ${ }^{87} \mathrm{Sr} /{ }^{86} \mathrm{Sr}$ dos dois sítios poderia ser explicada por diferenças na dieta, por diferenças geológicas nas principais áreas de captação de recursos - como um aumento na utilização de recursos continentais ou a utilização de fontes de água distintas - e pela presença de indivíduos provenientes de regiões com formação geológica mais antiga.

Sabemos que animais de regiões com disponibilidade isotópica diferente faziam parte da dieta tanto dos indivíduos do sítio Armação do Sul quanto Tapera, a exemplo dos porcos do mato com razões ${ }^{87} \mathrm{Sr} /{ }^{86} \mathrm{Sr}$ muito acima da média e outras amostras de fauna que se mostraram potencialmente não locais. Como o sítio Tapera está situado na baía sul, voltado para o continente, o acesso a esse tipo de recurso deveria ser facilitado. Além disso, as análises sobre alterações entésicas sugerem a transposição mais frequente de terrenos íngremes e acidentados pelos indivíduos masculinos do sítio Tapera. Nesse sentido, talvez os indivíduos desse sítio estivessem caçando tanto na mata atlântica - onde os terrenos são mais irregulares, demandando mais dos membros inferiores - quanto em áreas de baixadas, enquanto os indivíduos da Armação do Sul estariam caçando principalmente nas áreas de baixadas (Scherer et al. 2015).

Um foco maior nos recursos da mata atlântica - que, na Ilha de Santa Catarina, situa-se sobre granitos alcalinos do Eopaleozóico - poderia ser responsável pelo aumento nas razões isotópicas ${ }^{87} \mathrm{Sr}{ }^{86} \mathrm{Sr}$, ainda mais se tais recursos fossem buscados também na mata atlântica continental, onde a influência do estrôncio marinho sobre a assinatura biologicamente disponível é menor do que nas terras insulares. Ou, ainda, nos arredores dos atuais municípios de Biguaçu, São José e Palhoça, onde há presença de unidades geológicas que remetem ao Proterozóico e ao Arqueano.

A grande diferença observada nos coeficientes de variação (CVp), entretanto, é mais difícil de ser explicada para além da ideia de que, no sítio Tapera, a presença de indivíduos não locais provenientes de localidades litorâneas próximas teria sido mais expressiva. Como ambos os sítios estão inseridos em um mesmo contexto geológico, e como mesmo em regiões com grande heterogeneidade isotópica ${ }^{87} \mathrm{Sr} /{ }^{86} \mathrm{Sr}$ - a exemplo do litoral central - a tendência é de que grupos humanos e outros animais apresentem notável homogeneidade em suas assinaturas isotópicas (Price, Burton e Bentley 2002) - ainda mais em 
ambientes litorâneos com forte influência do estrôncio marinho (Bentley 2006) - os valores ${ }^{87} \mathrm{Sr} /{ }^{86} \mathrm{Sr}$ dos indivíduos dos sítios Armação do Sul e Tapera deveriam apresentar variação mais parecida.

Apesar da tendência à homogeneidade, existem fatores que podem introduzir variação nas razões ${ }^{87} \mathrm{Sr} /{ }^{86} \mathrm{Sr}$ de uma população, como a dieta. Para isso acontecer, contudo, precisa haver diferença na dieta de indivíduos ou grupos de indivíduos específicos (Price, Burton e Bentley 2002). Embora Bastos et al. (2015) tenham observado que algumas mulheres do sítio Tapera possivelmente estavam se alimentando de recursos com valores de $\delta^{13} \mathrm{C}$ mais negativos, não encontraram esse tipo de variabilidade na dieta do grupo analisado, nem qualquer correspondência entre a variação nas razões ${ }^{87} \mathrm{Sr} /{ }^{86} \mathrm{Sr}$ e os valores de $\delta^{15} \mathrm{~N}$ e $\delta^{13} \mathrm{C}$. No sítio Armação do Sul, embora não seja possível fazer correlações entre os valores $\delta^{15} \mathrm{~N}$ e $\delta^{13} \mathrm{C}$ do colágeno dos ossos e as assinaturas ${ }^{87} \mathrm{Sr} /{ }^{86} \mathrm{Sr}$ do esmalte dentário, pode-se dizer que não há tanta variabilidade na dieta: enquanto entre os indivíduos do sexo masculino foram, de fato, observadas diferenças, no grupo feminino a dieta é bastante homogênea e semelhante à das crianças fora da idade de amamentação.

Ficamos então com a hipótese de que a diferença na variação dos valores isotópicos ${ }^{87} \mathrm{Sr} /{ }^{86} \mathrm{Sr}$ entre os sítios Armação do Sul e Tapera esteja relacionada à uma expansão nas relações com populações litorâneas próximas, por parte dos indivíduos do sítio Tapera. Expansão tanto em termos quantitativos, com um aumento na frequência e intensidade dessas relações, quanto em termos qualitativos, com a incorporação de outras regiões isotópicas que, em tempos anteriores, talvez não estivessem incluídas na rede de relações. Em um momento anterior, representado pelo período 1 do sítio da Armação, as interações talvez fossem menos frequentes e/ou restritas a localidades específicas de disponibilidade isotópica mais parecida com a da Ilha de Santa Catarina, como a maior parte do continente próximo à ilha; no momento seguinte, representado pelo período 2, o processo expansivo teria se iniciado timidamente para, mais tarde, atingir seu auge em sítios como Tapera.

Se a hipótese estiver correta, essa expansão estaria se fazendo visível no registro arqueológico do sítio Tapera devido às trocas resultantes de um padrão virilocal de residência pós-marital, que aparecem no registro sob a forma de patrimônios genéticos (Hubbe 2009), assinaturas isotópicas (Bastos et al. 2015) e nos índices de robustez (Lessa et al. 2011). Provavelmente estaria também se manifestando por meio da presença de objetos, alimentos e costumes intercambiados, ainda por serem identificados em pesquisas futuras - como quem sabe a própria cerâmica.

Pensando agora no contexto do litoral catarinense como um todo e nas diferenças observadas entre os valores ${ }^{87} \mathrm{Sr} /{ }^{86} \mathrm{Sr}$ obtidos para as populações do litoral central e do litoral norte (Gráfico 9), enquanto os sítios Armação do Sul e Tapera apontam para um aumento da média e da variação das razões isotópicas em tempos mais tardios, no sítio Forte Marechal Luz, do litoral norte, a média e a variação das razões isotópicas permaneceram iguais ao longo dos mais de 3000 anos em que foi ocupado (Bastos et al. 2011).

Esses dados contribuem para uma melhor compreensão dos processos de mudança pelos quais passaram os sítios conchíferos catarinenses a partir de 2000 anos AP, chamando atenção para a forma como contextos locais diferentes respondem diferentemente a pressões estruturais possivelmente semelhantes. Nisso, colocam também em pauta a importância da relação entre indivíduo e estrutura nos processos de mudança social. A ação se dá por meio das disposições de indivíduos e grupos inseridos em contextos de significado específicos (Bourdieu 1967). Interpretações diferentes, ocasionadas por habitus distintos, podem levar a desdobramentos inimaginados, que fogem às pressões estruturais, tal como a morte do capitão Cook, quando estava indo embora no Havaí (Sahlins 1985). Daí a necessidade de se entender os processos de mudança contextualmente. 


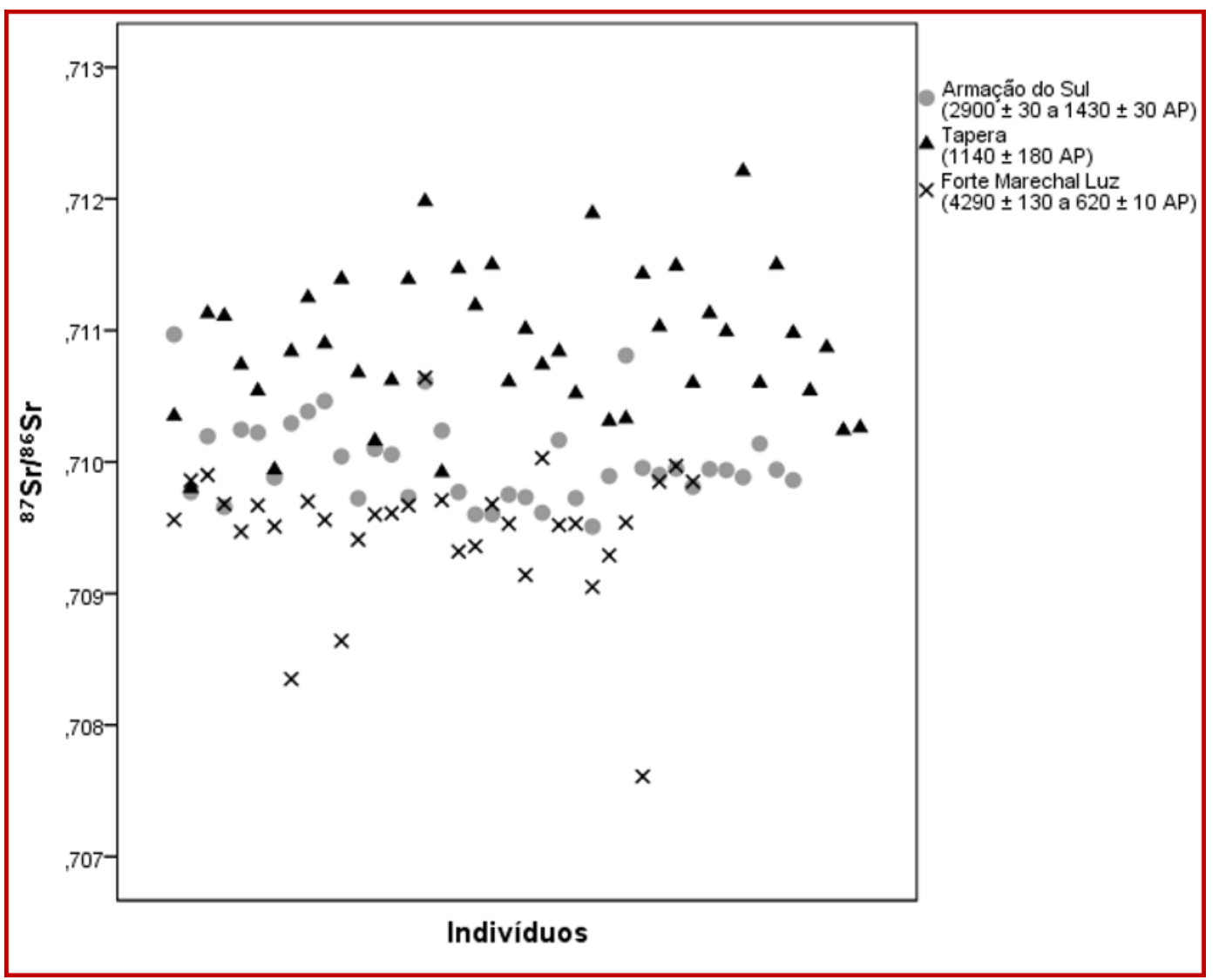

Gráfico 9: Dispersão dos valores ${ }^{87} \mathrm{Sr} /{ }^{86} \mathrm{Sr}$ dos indivíduos analisados do sítio Armação do Sul, Tapera (Bastos et al. 2015) e Forte Marechal Luz (Bastos et al. 2011). Na legenda constam as faixas temporais ocupadas por cada sítio, definidas a partir de suas idades radiocarbônicas convencionais.

As razões isotópicas ${ }^{87} \mathrm{Sr} /{ }^{86} \mathrm{Sr}$ indicam que acontecimentos possivelmente semelhantes, de ordem cultural e/ou ambiental - como a diminuição do nível do mar, o aumento da umidade, o contato intercultural ou qualquer outro evento que tenha se dado em escala regional - se desenrolaram diferentemente no litoral norte e no litoral central de Santa Catarina. A população do sítio Forte Marechal Luz (Bastos et al. 2011) manteve o mesmo padrão de mobilidade após o aparecimento da cerâmica, com manutenção da média dos valores isotópicos e incorporação eventual de indivíduos de outras regiões litorâneas. A população do sítio Tapera (Bastos et al. 2015), de certa forma, também manteve o padrão de mobilidade observado no sítio Armação do Sul, caracterizado por uma pequena - porém crescente - variação nos valores isotópicos, no entanto, apresentou valores ainda mais altos, elevando tanto a média dos valores quanto o seu coeficiente de variação.

O que parece é que na interpretação local de acontecimentos regionais, a população associada ao sítio Forte Marechal Luz manteve-se circunscrita em torno dela mesma. Enquanto isso, as populações do sítio Armação do Sul e Tapera tornaram-se ainda mais abertas do que eram, expandindo suas fronteiras - pelo menos no sentido de trocas culturais e/ou pessoas - para regiões litorâneas próximas, com presença de formações geológicas mais antigas, como ocorre em alguns pontos entre Porto Belo e Balneário Camboriú, mais ao norte, e no município de São José, no continente próximo.

Ademais, a constatação da existência de diferença significativa entre as médias das assinaturas de ${ }^{87} \mathrm{Sr} /{ }^{86} \mathrm{Sr}$ dos sítios em questão nos dá um maior poder interpretativo frente aos dados, mostrando que indivíduos provenientes do litoral norte podem vir a ser identificados quando estiverem sepultados em sítios do litoral central e vice-versa. Mesmo que as variações nas assinaturas isotópicas disponíveis ao longo do litoral catarinense sejam pequenas - mais por causa da influência do estrôncio marinho do que da geologia - o fato dos espectrômetros de massa modernos apresentarem precisão mínima de $10^{-5}($ Allègre 
2008) torna variações na quarta casa decimal extremamente significativas, podendo ser utilizadas para identificar indivíduos não locais (Grupe et al. 1997).

Com um aprofundamento dos estudos e mapeamento das pequenas variações ao longo do litoral, portanto, os isótopos de estrôncio poderão passar a informar não apenas sobre as relações estabelecidas com populações do interior e outras regiões litorâneas mais distantes, mas também sobre as relações estabelecidas - fluxos de ideias, objetos e pessoas - entre as populações das diferentes porções do litoral catarinense, colocando-se como um caminho possível para a melhor compreensão das redes de inter-relações na paisagem pré-colonial do litoral de Santa Catarina.

\section{CONSIDERAÇÕES FINAIS}

As coisas não mudaram da mesma forma em todas as porções litorâneas catarinenses. Embora as populações associadas aos sítios conchíferos dessa faixa costeira compartilhassem inúmeras tradições e vivências de mundo que deveriam conferir-lhes uma identidade coletiva, estruturando e sendo estruturadas por suas práticas, como a dieta, a tecnologia, a íntima relação com ambientes estuarinos, a distribuição dos sítios no entorno de formações lagunares, a resposta à crise biológica e social da morte e a monumentalização das áreas funerárias pela deposição de material faunístico e sedimento; e, embora haja sintonia cronológica entre muitos dos acontecimentos observados, os habitus e contextos locais geraram um efeito de refração, influenciando a apreensão de tais acontecimentos enquanto eventos e, assim, seus desenrolares. A ideia é de processos de mudança que se interseccionaram em determinados pontos no tempo e no espaço, porém, bifurcaram-se em direções, intensidades e atores distintos.

No caso do sítio Armação do Sul, as mudanças estão relacionadas a um quadro que envolveu maior circulação e incorporação de indivíduos de diferentes partes do litoral central e mudança na dieta dos indivíduos masculinos. Associando esses elementos com outros que foram levantados em Oppitz (2015), é possível seguir a deixa de Bourdieu (1967) ao ponderar o surgimento do estilo gótico e esboçar um quadro de séries causais independentes na ordem da causalidade, cuja combinação ou encontro engendrou mudanças significativas na vivência de mundo da população associada ao sítio Armação do Sul e no registro arqueológico. Tal quadro de acontecimentos inter-relacionados envolveu: maior circulação e incorporação de indivíduos de diferentes partes do litoral central; mudança na dieta de parte dos indivíduos do sexo masculino em direção à diminuição no consumo de recursos marinhos de alto nível trófico e/ou ao consumo de recursos terrestres (talvez plantas $\mathrm{C}_{4}$ ou animais que delas se alimentam); desenvolvimento de uma distinção social mais claramente observável no registro arqueológico e, possivelmente, hereditária ${ }^{11}$; aumento da violência que, apesar de ser um caso isolado no sítio Armação do Sul, ganha força quando considerado juntamente com os demais casos do litoral central (Base Aérea e Tapera) (Lessa e Scherer 2008); inovações em alguns elementos que compõem as práticas mortuárias (abandono do uso do ocre, introdução de pontas ósseas e artefatos fusiformes) (Oppitz 2015); mudança no sedimento que compõe o sítio (Schmitz et al. 1992); adensamento populacional ou maior quantidade de indivíduos sendo sepultados no mesmo local (Oppitz 2015); transição para um padrão de residência virilocal (Hubbe et al. 2009); alterações paleoclimáticas (aumento da umidade) (Stríkis et al. 2011, Novello et al. 2012) e paleogeográficas (devido à diminuição no nível do mar) (Castilhos 1995).

\footnotetext{
11 O fato de alguns sepultamentos infantis acompanharem a mudança nas práticas mortuárias relacionadas aos indivíduos masculinos (aumento da variabilidade no número e nos tipos de acompanhamentos, com presença mais frequente de sepultamentos que se destacam pela suntuosidade) e justamente na incorporação de elementos tipicamente masculinos (Oppitz 2015), indica que podemos estar lidando com a passagem de uma sociedade de status adquirido para uma sociedade de status hereditário (Marcus 2008). Em diferentes contextos ao redor do mundo, os sepultamentos infantis raramente se mostram tão elaborados quanto os dos adultos (Fahlander 2008). Sepultamentos ricos em objetos, contudo, ocorrem, e são frequentemente entendidos como evidência de desigualdade hereditária (Marcus 2008): sendo as crianças muito novas para terem adquirido o direito de possuir tantos objetos, deveriam ter herdado tal direito e o status correspondente.
} 
Trata-se de uma rede de causalidades locais, regionais e globais sincrônica e diacronicamente inter-relacionadas, na qual se incluem desde acontecimentos mais prosaicos, como a inovação no contexto de uso das pontas ósseas e artefatos fusiformes, até a atividade solar e o vulcanismo do mundo, responsáveis pelas mudanças ambientais no litoral de Santa Catarina.

O cenário é de intensificação nos processos de mudança, de transição; e, resguardadas as idiossincrasias locais, envolve uma associação de acontecimentos possíveis que é recorrente em diferentes contextos de mudança ao redor do mundo. Ao fim, as inferências realizadas configuram-se em um cenário coerente, indicando que, talvez, estejamos no caminho certo. Estava tudo acontecendo ao mesmo tempo, e a população associada ao sítio Armação do Sul viveu, em seus próprios termos, seus próprios tempos de mudança.

\section{Agradecimentos}

Agradecemos à equipe do CPGeo/USP, do Laboratório de Ecologia Isotópica do CENA/USP, do Laboratório de Paleoparasitologia da ENSP/FIOCRUZ e do Laboratório de Sistemas Cársticos do IGc/USP. Em especial à Liliane Petronilho, à Fabiana Fracassi e ao Prof. Dr. Marcelo Moreira, que estiveram mais diretamente envolvidos nas análises. Agradecemos também aos pareceristas, que contribuíram para a versão final deste artigo, com comentários e sugestões valiosas. 


\section{REFERÊNCIAS}

ALLÈGRE, Claude J. (2008). Isotope Geology. Cambridge, Cambridge University Press. 512pp.

AMBROSE, Stanley H. (1993). Isotopic analysis of paleodiets: methodological and interpretive considerations. In: Sandford, M.K. (Ed.). Investigations of Ancient Human Tissue. Gordon and Breach. p. 59-130.

ATALAY, Sonya; HASTORF, Christine A. (2006). Food, Meals, and Daily Activities: Food Habitus at Neolithic Çatalhöyük. American Antiquity, 71(2):283-319.

BANDEIRA, Dione R. (1992). Mudança na estratégia de subsistência: o sítio arqueológico Enseada I - um estudo de caso. Dissertação de Mestrado. Florianópolis, Universidade Federal de Santa Catarina. 145pp.

BANDEIRA, Dione R. (2004). Ceramistas pré-coloniais da baía da Babitonga, SC-arqueologia e etnicidade. Tese de Doutorado. Campinas, Universidade Estadual de Campinas. 257pp.

BARTHES, Roland. (1979). Toward a Psychosociology of Contemporary Food Consumption In: FOSTER, R.; RANUM, O. (Eds.) (1979). Food and drink in history. Baltimore, John Hopkins University Press.

BASTOS, Murilo Q.R.; LESSA, Andrea.; CARVALHO, Cláudia R.; TYKOT, Robert H.; SANTOS, Roberto V. (2014). Análise de carbono e nitrogênio: a dieta antes e após a presença de cerâmica no sítio Forte Marechal Luz. Revista do Museu de Arqueologia e Etnologia,24: 137-151.

BASTOS, Murilo Q.R.; MENDONÇA DE SOUZA, Sheila F.; SANTOS, Roberto V.; LIMA, Barbara A.F.; SANTOS, Ricardo V., RODRIGUES-CARVALHO, Cláudia R. (2011). Human mobility on the Brazilian coast: analysis of strontium isotopes in archaeological human remains from the sambaqui of Forte Marechal Luz. Anais da Academia Brasileira de Ciências, 83(2): 731-743.

BASTOS, Murilo Q.R.; SANTOS, Roberto V.; TYKOT, Robert H.; SOUZA, Sheila F.M.; CARVALHO, Cláudia R.; LESSA, Andrea. (2015). Isotopic evidences regarding migration at the archaeological site of Praia da Tapera: New data to an old matter. Journal of Archaeological Science: Reports, 4: 588-595.

BENDAZZOLI, Cíntia. (2007). O processo de formação dos sambaquis: uma leitura estratigráfica do sítio Jabuticabeira II. Dissertação de Mestrado. São Paulo, Universidade de São Paulo. 246pp.

BENDER, Margaret M. (1968). Mass Spectrometric Studies of Carbon 13 Variations in Corn and Other Grasses. Radiocarbon, 10(2):468-472.

BENTLEY, R. Alexander. (2006). Strontium isotopes from the Earth to the archaeological skeleton: a review. Journal of Archaeological Method and Theory, 13(3): 135-187.

BENTLEY, R. Alexander; KRAUSE, Rüdiger; PRICE, T. Douglas; KAUFMANN, Bruno. (2003). Human mobility at the early Neolithic settlement of Vaihingen, Germany: evidence from strontium isotope analysis. Archaeometry, 45(3): 471-486.

BORRERO, Luis Alberto; BARBERENA, Ramiro. (2006). Hunter-Gatherer Home Ranges and Marine Resources: An Archaeological Case from Southern Patagonia. Current Anthropology, v. 47, n. 5: 855-868.

BOURDIEU, Pierre. (1967). Estruturas, Habitus e Prática. In: BOURDIEU, P. (2011). A economia das trocas simbólicas. São Paulo, Perspectiva. 361pp.

BOURDIEU, Pierre. (1977). Outline of a theory of practice. Cambridge: Cambridge University Press.

BOURDIEU, Pierre. (1989). O poder do simbólico. Rio de Janeiro, Bertrand Brasil. 311pp. 
BOYADJIAN, Célia Helena Cezar; EGGERS, Sabine.; REINHARD, Karl; SCHEEL-YBERT, Rita. (2016). Dieta no sambaqui Jabuticabeira-II (SC): consumo de plantas revelado por microvestígios provenientes de cálculo dentário. $C a$ dernos do LEPAARQ, 13(25):131-161.

BRAUDEL, Fernand. (1984). O Mediterrâneo e o mundo mediterrânico na época de Filipe II. Vol. 1, 2, 3. São Paulo, Martins Fontes.

BRAUDEL, Fernand. (1992 [2005]). Escritos sobre a História. São Paulo, Perspectiva.

CASTILHOS, Janete A. (1995). Estudo evolutivo, sedimentológico e morfodinâmico da planície costeira e praia da Armação - Ilha de Santa Catarina, SC. Dissertação de Mestrado. Florianópolis Universidade Federal de Santa Catarina.

CHMYZ, Igor. (1967). Dados parciais sobre a arqueologia do vale do rio Paranapanema. ln: Programa Nacional de Pesquisas Arqueológicas: resultados preliminares do primeiro ano 1965-1966. Museu Paraense Emílio Goeldi, publicações avulsas, Belém, 6: 59-78.

CHMYZ, Igor. (1968). Considerações sobre duas novas tradições ceramistas arqueológicas no Estado do Paraná. Anais do Segundo Simpósio de Arqueologia da Área do Prata. Pesquisas, Antropologia, São Leopoldo, 18:115-125.

COLONESE, André Carlo; COLLINS, Matthew; LUCQUIN, Alexandre; EUSTACE, Michael; HANCOCK, Yvette; PONZONI, Raquel A.R.; MORA, Alice; SMITH, Colin; DeBLASIS, Paulo; FIGUTI, Levy; WESOLOWSKI, Verônica; PLENS, Cláudia R.; EGGERS, Sabine; FARIAS, Deisi S.E.; GLENDHILL, Andy; CRAIG, Oliver E.; (2014). Long-Term Resilience of Late Holocene Coastal Subsistence System in Southeastern South America. PLOS ONE, 9(4): e93854.

COMERLATO, Fabiana. (2005) As representações rupestres do litoral de Santa Catarina. Tese de Doutorado. Porto Alegre, Pontifícia Universidade Católica do Rio Grande do Sul. 317pp.

DeBLASIS, Paulo; KNEIP, Andreas; SCHEEL-YBERT, Rita; GIANINNI, Paulo César; GASPAR, Maria Dulce. (2007). Sambaquis e paisagem: dinâmica natural e Arqueologia regional no litoral do sul do Brasil. Revista Arqueología Suramericana, 3: 29-61.

DeBLASIS, Paulo; GASPAR, Maria Dulce. (2008/2009). Os sambaquis do sul Catarinense: retrospectiva e perspectiva de dez anos de pesquisas. Especiaria - Cadernos de Ciências Humanas, Ilhéus, 20/21 (11/12): 83-125.

DE MASI, Marco Aurélio N. (2001). Pescadores coletores da costa sul do Brasil. Pesquisas, Antropologia, São Leopoldo, 57. $136 \mathrm{pp}$.

DE MASI, Marco Aurélio N. (2009). Aplicações de isótopos estáveis de 18/16O, 13/12C e 15/14N em estudos de sazonalidade, mobilidade e dieta de populações pré-históricas no sul do Brasil. Revista de Arqueologia, 22(2): 55-76.

DeNIRO, Michael J.; EPSTEIN, Samuel. (1978). Influence of diet on the distribution of carbon isotopes in animals. Geochimica et Cosmochimica Acta, 42:495-506.

DeNIRO, Michael J.; EPSTEIN, Samuel. (1981). Influence of diet on distribution of nitrogen isotopes in animals. Geochimica et Cosmochimica Acta, 45:341-351.

DOUGLAS, Mary. (1972). Deciphering a Meal. Daedalus, 101: 61-81.

ELIAS, Norbert. (1994[1939]). O processo civilizador Vol. 1: Uma História dos Costumes. Rio de Janeiro, Jorge Zahar Editor. $277 \mathrm{pp}$.

FARIAS, Deisi S.E.; KNEIP, Andreas. (2010). Panorama arqueológico de Santa Catarina. Palhoça, Editora Unisul. 306pp FIGUTI, Levy. (1993). O homem pré-histórico, o molusco e os sambaquis: considerações sobre a subsistência dos povos sambaquieiros. Revista do Museu de Arqueologia e Etnologia, São Paulo, 3: 67-80. 
FOSSARI, Teresa D. (2004). A população pré-colonial Jê na paisagem da Ilha de Santa Catarina. Tese de Doutorado (Doutorado em Geografia). Florianópolis, Universidade Federal de Santa Catarina. 339pp.

GIANNINI, Paulo César F.; VILLAGRAN, Ximena S.; FORNARI, Milene; NASCIMENTO JÚNIOR, Daniel R.; MENEZES, Priscila M.L.; TANAKA, Ana Paula B.; ASSUNÇÃO, Danilo C.; DeBLASIS, Paulo; AMARAL, Paula G.C. (2010). Interações entre evolução sedimentar e ocupação humana pré-histórica na costa centro-sul de Santa Catarina, Brasil. Boletim do Museu Paraense Emílio Goeldi, Ciências Humanas, Belém, 5(1): 105-128.

GOSDEN, Christopher. (2005). What do objects want? Journal of archaeological method and theory, 12(3): $193-211$.

GRUPE, Gisela; PRICE, T. Douglas; SCHROTER, Peter; SOLLNER, Frank; JOHNSON, Clark M.; BEARD, Brian L. (1997). Mobility of Bell Beaker people revealed by strontium isotope ratios of tooth and bone: a study of southern Bavarian skeletal remains. Applied Geochemistry, 12: 517-525.

HANSEL, Fabrício A.; SCHMITZ, Pedro Ignácio. (2006). Classificação e interpretação dos resíduos orgânicos preservados em fragmentos de cerâmica arqueológica por cromatografia gasosa e cromatografia gasosa - espectrometria de massas. Pesquisas, Antropologia, São Leopoldo, 63: 81-112.

HUBBE, Mark; NEVES, Walter; OLIVEIRA, Emiliano C.; STRAUSS, André. (2009). Postmarital residence practice in Southern Brazilian coastal groups: continuity and change. Latin American Antiquity, 20(2):1-12.

KATZENBERG, M. Anne; HARRISON, Roman G. (1997). What's in a Bone? Recent Advances in Archaeological Bone Chemistry. Journal of Archaeological Research, 5(3):265-293.

KATZENBERG, M. Anne; HERRING, D. Ann; SAUNDERS, Shelley R. (1996). Weaning and Infant Mortality: Evaluating the Skeletal Evidence. Year book of Physical Anthropology, 39:177-199.

KLÖKLER, Daniela M. (2001). Construindo ou deixando um sambaqui? Análise de sedimentos de um sambaqui do litoral meridional brasileiro: processos formativos. Região de Laguna, SC. Dissertação de Mestrado. São Paulo, Universidade de São Paulo. 164pp.

KLÖKLER, Daniela M. (2008). Food for body and soul: mortuary ritual in shell mounds (Laguna-Brazil). Tese de Doutorado, Tucson, Universidade do Arizona. 369pp.

KLÖKLER, Daniela M. (2014). A ritually constructed shell mound: feasting at the Jabuticabeira II site. In: ROKSANDIC, Mirjana; MENDONÇA DE SOUZA, Sheila; KLÖKLER, Daniela; EGGERS, Sabine; BURCHELL, Meghan. The cultural dynamics of shell middens and shell mounds: a worldwide perspective. Albuquerque: University of New Mexico Press. p.151-163

KNUDSON, Kelly J; PRICE, T. Douglas; BUIKSTRA, Jane E.; BLOM, Deborah E. (2004). The use of strontium isotope analysis to investigate Tiwanaku migration and mortuary ritual in Bolivia and Peru. Archaeometry, 46(1): 5-18.

LARSEN, Clark S. (2015[1997]). Isotopic and elemental signatures of diet, nutrition, and life history. In: LARSEN, Clark S. (2015[1997]). Bioarchaeology: interpreting behavior from the human skeleton. Cambridge: Cambridge University Press. p. 301-356.

LEE-THORP, Julia A.; SEALY, Judith C.; VAN DER MERWE, Nikolaas J. (1989). Stable Carbon Isotope Ratio Differences Between Bone Collagen and Bone Apatite, and their Relationship to Diet. Journal of Archaeological Science, 16:585-599.

LESSA, Andrea; SCHERER, Luciane Z. (2008). O outro lado do paraíso: novos dados e reflexões sobre violência entre pescadores-coletores pré-coloniais. Revista do Museu de Arqueologia e Etnologia, 18:89-100. 
LESSA, Andrea; BASTOS, Murilo Q.R.; SCHERER, Luciane Z. (2011). Robustez pós-craniana em uma série de pescadorescaçadores do litoral sul. Resumos do XVI Congresso da Sociedade de Arqueologia Brasileira, Florianópolis.

MAKAREWICZ, Cheryl A.; SEALY, Judith. (2015). Dietary reconstruction, mobility, and the analysis of ancient skeletal tissues: expanding the prospects of stable isotope research in archaeology. Journal of Archaeological Science, 56: 146-158.

MILHEIRA, Rafael G. (2010). Arqueologia Guarani no litoral sul-catarinense: história e território. Tese de Doutorado. São Paulo, Universidade de São Paulo.

MONTGOMERY, Janet; EVANS, Jane A.; NEIGHBOUR, Tim. (2003). Sr isotope evidence for population movement within the Hebridean Norse community of NW Scotland. Journal of the Geological Society, 160(5): 649-653.

MÜLlER, Isabela S. (2014). Arqueologia Guarani no Litoral Central de Santa Catarina: estudo de caso do sítio Travessão do Rio Vermelho (TRV). Trabalho de Conclusão de Curso. Florianópolis, Universidade Federal de Santa Catarina.

NEVES, Walter. (1988). Paleogenética dos grupos pré-históricos do litoral sul do Brasil (Paraná e Sana Catarina). Pesquisas, Antropologia, São Leopoldo, 43. 178pp.

NISHIDA, Paula. (2007). A coisa ficou preta: estudo do processo de formação da terra preta do sítio arqueológico Jabuticabeira II. Tese de Doutorado. São Paulo, Universidade de São Paulo. 112pp.

NOVELLO, Valdir F.; CRUZ, Francisco W.; KARMANN, Ivo; BURNS, Stephen J.; STRÍKIS, Nicolás M.; VUILLE, Mathias; CHENG, Hai; EDWARDS, R. Lawrence; SANTOS, Roberto V.S.; FRIGO, Everton; BARRETO, Eline A.S. (2012). Multidecadal climate variability in Brazil's Nordeste during the last 3000 years based on speleothem isotope records. Geophysical Research Letters, 39:L23706.

OKUMURA, Maria Mercedes. (2008). Diversidade morfológica craniana, micro-evolução e ocupação pré-histórica da costa brasileira. Pesquisas, Antropologia, São Leopoldo, 66. 306pp.

OPPITZ, Gabriela. (2011). Vivendo a paisagem: contribuições transdisciplinares para o estudo do contexto regional de sambaquis do litoral central de Santa Catarina. Trabalho de Conclusão de Curso. Florianópolis, Universidade Federal de Santa Catarina. 137pp.

OPPITZ, Gabriela. (2015). Coisas que mudam: os processos de mudança nos sitios conchiferos catarinenses e um olhar isotópico sobre o caso do sítio Armação do Sul, Florianópolis/SC. Dissertação de Mestrado. São Paulo, Universidade de São Paulo. 282pp.

PRICE, T. Douglas.; BURTON, James H.; BENTLEY, R. Alexander. (2002). The characterization of biologically available strontium isotope ratios for the study of Prehistoric migration. Archaeometry, 44: 117-135.

ROHR, João Alfredo. (1974). Armação do Sul: três mil anos de história. Correio do Povo, Porto Alegre.

ROHR, João Alfredo; ANDREATTA, Margarida. (1969). O sítio arqueológico da Armação do Sul (nota prévia). In: Anais do Terceiro Simpósio de Arqueologia da Área do Prata. Pesquisas, Antropologia, 20, Estudos Leopoldenses, 13:135138.

SAHLINS, Marshall. (1976[2003]). Cultura e Razão Prática. Rio de Janeiro, Jorge Zahar Editor.

SAHLINS, Marshall. (1985[2011]). Ilhas de História. Rio de Janeiro, Zahar. 250pp.

SCHEEL-YBERT, Rita; EGGERS, Sabine; WESOLOWSKI, Verônica; PETRONILHO, Cecilia C.; BOYADJIAN, Célia Helena; DeBLASIS, Paulo; BARBOSA-GUIMARÃES, Márcia; GASPAR, Maria Dulce. (2003). Novas perspectivas na reconstituição do modo de vida dos sambaquieiros: uma abordagem multidisciplinar. Revista Arqueologia, 16: 109-137. 
SCHEEL-YBERT, Rita. (2013) Antracologia: preservados pelo fogo. In: GASPAR, Maria Dulce; MENDONÇA DE SOUZA, Sheila M. (Org.). Abordagens estratégicas em sambaquis. Erechim: Habilis, p. 193-218.

SCHERER, Luciane Z.; LESSA, Andrea; SALLES, Adilson D. (2015). Alterações entésicas e mobilidade terrestre em grupos pré-coloniais litorâneos do sul do Brasil. Revista do Museu de Arqueologia e Etnologia, 25: 21-44.

SCHMITZ, Pedro Ignácio; DE MASI, Marco Aurélio N.; VERARDI, Ivone; LAVINA, Rodrigo; JACOBUS, André Luiz. (1992). O sítio arqueológico da Armação do Sul. Pesquisas, Antropologia, São Leopoldo, 48. 220pp.

SCHOENINGER, Margaret J.; DeNIRO, Michael J.; TAUBER, Henry. (1983). Stable nitrogen isotope ratios of bone collagen reflect marine and terrestrial components of prehistoric human diet. Science, New Series, 220 (4604): 1381-1383.

SCHOENINGER, Margaret J.; MOORE, Katherine. (1992). Bone Stable Isotopes Studies in Archaeology. Journal of World Prehistory, 2:247-296.

SMITH, Bruce N.; EPSTEIN, Samuel. (1971). Two Categories of 13C/12C Ratios for Higher Plants. Plant Physiol. 47:380384.

STRÍKIS, Nicolás M.; CRUZ, Francisco W.; CHENG, Hai; KARMANN, Ivo; EDWARDS, R. Lawrence; VUILLE, Mathias, WANG, Xianfeng; de PAULA, Marcos S.; NOVELlO, Valdir F.; AULER, Augusto S. (2011). Abrupt variations in South American monsoon rainfall during the Holocene based on speleothem record from central-eastern Brazil. Geology, 39: 1075-1078.

VILLAGRAN, Ximena S. (2008). Análise de arqueofácies na camada preta do sambaqui Jabuticabeira II. São Paulo, Universidade de São Paulo. 170pp.

VILLAGRAN, Ximena S.; KLOKLER, Daniela; NISHIDA, Paula G.; GASPAR, Maria Dulce; DeBLASIS, Paulo. (2010). Lecturas estratigráficas: arquitectura funerária y depositación de resíduos en el sambaquí Jabuticabeira II. Latin American Antiquity, 21: 195-216.

VILLAGRAN, Ximena S. (2012). Micromorfologia de sítios concheiros da América do Sul: arqueoestratigrafia e processos de formação de sambaquis (Santa Catarina, Brasil) e concheros (Terra do Fogo, Argentina). São Paulo, Universidade de São Paulo. 493pp.

WALKER, Phillip. L.; DeNIRO, Michael J. (1986). Stable nitrogen and carbone isotopic ratios in bone collagen as indices of prehistoric dietary dependence on marine and terrestrial resources in Southern California. American Journal of Physical Anthropology, 71: 51-61.

WESOLOWSKI, Verônica. (2007). Cáries, desgaste, cálculos dentários e micro-resíduos da dieta entre grupos pré-históricos do litoral norte de Santa Catarina. É possível comer amido e não ter cárie? Tese de Doutorado. Rio de Janeiro, Fundação Oswaldo Cruz. 188pp.

WRIGHT, Lori E. (2005). Identifying immigrants to Tikal, Guatemala: defining local variability in strontium isotope ratios of human tooth enamel. Journal of Archaeological Science, 32: 555-566.

Recebido em: 30/02/2018

Aprovado em: 30/06/2018

Publicado em: 30/11/2018 